\title{
Emprego de polímeros de impressão molecular em preparo de amostras para análise de compostos orgânicos: aplicações e tendências
}

\author{
Mariane Gonçalves Santos, Lailah Cristina de Carvalho Abrão, \\ Lissara Aparecida de Souza Freitas, Gabriel de Oliveira Isac Moraes, \\ Marcela Marília de Lima, Eduardo Costa Figueiredo* \\ Laboratório de Análises de Toxicantes e Fármacos - LATF, Faculdade de Ciências Farmacêuticas, \\ Universidade Federal de Alfenas - UNIFAL, Rua Gabriel Monteiro da Silva, 700, Cep 37130-000, Alfenas, MG, Brasil \\ e-mail:eduardocfig@yahoo.com.br
}

\section{Resumo}

Os polímeros de impressão molecular são materiais sintéticos dotados de sítios específicos de reconhecimento. Esses materiais são obtidos por reações de polimerização que fixam, estrategicamente, monômeros funcionais ao redor de uma molécula modelo de acordo com os grupos ligantes e com a estereoquímica de ambas as moléculas. Os MIPs têm sido amplamente empregados em procedimentos de preparo de amostras, como extração e microextração em fase sólida, extração sortiva em barra de agitação, extração com adsorvente magnético, microextração com sorvente empacotado, entre outras. Este artigo de revisão tem como objetivo apresentar o que há de mais recente no emprego de MIP para extração de compostos orgânicos, evidenciando as vantagens de cada aplicação, bem como as mais promissoras tendências que sustentam a evolução e o aperfeiçoamento de cada técnica.

Palavras-chave

Polímeros de impressão molecular; MIP; preparo de amostras.

\section{Molecularly imprinted polymers in sample preparation for organic compounds analysis: applications and trends}

\section{Abstract}

Molecularly imprinted polymers are synthetic materials with molecular recognition ability. These materials are obtained by polymerization reactions that fix the functional monomers around the template molecule according with the binding groups and the stereochemistry of both molecules. The MIPs have been extensively used in several applications with emphasis for sample preparation procedures as solid phase extraction, solid phase microextraction, extraction by magnetic sorbents, microextraction by packed sorbent among others. So, the objective of this review is to present the novelty in MIP use for organic compounds extraction and point out the advantages of each application, as well as what is most promising in the evolution and improvement of each technique.

Keywords

Molecularly imprinted polymers; MIP; sample preparation. 


\section{Introdução}

O preparo de amostras certamente é a etapa mais importante do processo analítico, principalmente porque é a maior fonte de erros de imprecisão e inexatidão ${ }^{[1]}$. Essas técnicas têm como objetivos extrair, isolar e concentrar os analitos de interesse, transferindo-os para um meio que possa ser introduzido diretamente no sistema analítico ${ }^{[2]}$. Um preparo de amostra ideal deve agregar características tais como: eliminação de interferentes da matriz, perda mínima da amostra, pré-concentração do analito, boa recuperação, compatibilidade com a técnica de detecção, simplicidade, robustez, reprodutibilidade, rapidez e, preferencialmente, baixo custo ${ }^{[2]}$. Levantamentos realizados na década de 90 mostraram que o preparo de amostras é responsável por consumir pelo menos $61 \%$ do tempo total de uma análise, e mais de $80 \%$ desse tempo quando em associação com a etapa de amostragem ${ }^{[1,3]}$.

Apesar dos avanços alcançados no desenvolvimento de equipamentos analíticos de alta eficiência, é possível observar que o preparo de amostras ainda é pouco explorado quando comparado com as demais etapas analíticas. A complexidade e a presença de muitos concomitantes na matriz (muitas vezes em concentrações maiores do que a das substâncias de interesse) fazem com que o pré-tratamento seja indispensável e deveras difícil ${ }^{[4-6]}$.

O preparo de amostras pode ser classificado em exaustivo ou não exaustivo, de acordo com a forma usada para extrair os analitos da matriz. $\mathrm{O}$ processo exaustivo tem como objetivo a remoção completa dos analitos e sua transferência para a fase extratora. As técnicas não exaustivas são baseadas em princípios de equilíbrio, uma vez que a capacidade da fase extratora é pequena e insuficiente para a completa remoção dos anali$\operatorname{tos}^{[7]}$.
As técnicas de preparo de amostras mais usualmente utilizadas são: extração líquido-líquido (LLE), extração em fase sólida (SPE), microextração em fase líquida (LPME), microextração em fase sólida (SPME), headspace, extração em fluído supercrítico (SFE), extração sortiva com barras de agitação (SBSE), entre outras. Contudo, apesar de se mostrarem eficientes, estas técnicas convencionalmente podem apresentar pouca seletividade quando empregam sorventes convencionais. Além disso, as técnicas miniaturizadas como LPME e SPME normalmente apresentam baixa capacidade de pré-concentração devido à pequena quantidade de sorvente, prejudicando a identificação e a quantificação das substâncias de interesse ${ }^{[8-10]}$.

Uma possibilidade bastante explorada nas últimas décadas para solucionar estes problemas é a utilização de polímeros molecularmente impressos (MIPs). Os MIPs são considerados sorventes dotados de seletividade melhorada para certa substância ou para um grupo de substâncias estruturalmente semelhantes ${ }^{[11]}$. A história da impressão molecular teve início com os experimentos de Polyakov ${ }^{[12]} \mathrm{em}$ 1931, que conseguiu demonstrar que a seletividade molecular poderia ser impressa em sílica gel por pré-tratamento do ácido silícico com adsorbatos orgânicos antes de sua policondensação. Mais tarde Dickey, nas décadas de 1940 e $1950,{ }^{[13,14]}$ realizou investigações mais extensas. Dickey precipitou ácido silícico na presença de corantes alquilo e descobriu que, após a secagem do hidrogel e removendo o excesso dos agentes impressores, o que resultou foi um xerogel com uma capacidade de adsorção grandemente aumentada para o corante em questão. Os polímeros orgânicos apareceram pela primeira vez na década de 1970, quando polímeros de vinila foram impressos covalentemente por Wulff e Sarhan ${ }^{[15]}$. A impressão não covalente, como é 
conhecida nos dias atuais, foi introduzida uma década depois, com a publicação de trabalhos sobre aplicações generalizadas dos MIPs em muitos campos diferentes ${ }^{[16,17]}$. Desde então foi possível observar um enorme crescimento no número de publicações referentes ao uso dos MIPs, principalmente a partir da década de 1990, quando este crescimento passou a ser exponencial ${ }^{[18]}$.

Os MIPs são materiais rígidos e tridimensionais sintetizados ao redor de uma molécula modelo (MM) por meio de ligações covalentes ou não covalentes. Os sítios de reconhecimento são obtidos pelo arranjo de monômeros funcionais (MFs) polimerizáveis ao redor da MM. Os complexos são fixados através de reações de entrecruzamento de polímeros e, após a remoção da MM da matriz polimérica, os sítios específicos de reconhecimento são expostos, exibindo afinidade à MM (Figura 1) ${ }^{[19-24]}$.

Desde que o primeiro trabalho sobre MIPs para extrações em fase sólida (MISPE) foi apresentado por Sellergren em 1994, ${ }^{[25]}$ diversos artigos que tratam da utilização de MIPs no preparo de amostras têm sido publicados para a análise de vários tipos de matrizes como fluidos biológicos, amostras de alimentos, amostras ambientais, entre outras.

Nos métodos bioanalíticos, os MIPs vêm sendo utilizados para o isolamento e pré-concentração de uma grande variedade de analitos em fluidos biológicos, tais como urina, saliva, soro, plasma $^{[19,26-28]}$ e amostras de tecido, como cabelo e fígado ${ }^{[29,30]}$. O primeiro exemplo de aplicação de MIPs em análise de amostras biológicas foi relatado por Sellergren ${ }^{[25]}$ para determinação de pentamidina em urina. Desde então, ficou claro que uma otimização cuidadosa de todas as variáveis de extração é indispensável para o sucesso do uso de MIPs em preparo de amostras.

Em análises ambientais, os polímeros impressos têm sido empregados para a extração de praguicidas, produtos farmacêuticos, compostos fenólicos, entre outros, em amostras de água, sedimento e solo ${ }^{[31-34]}$. O primeiro trabalho que descreveu este tipo de aplicação dos MIPs

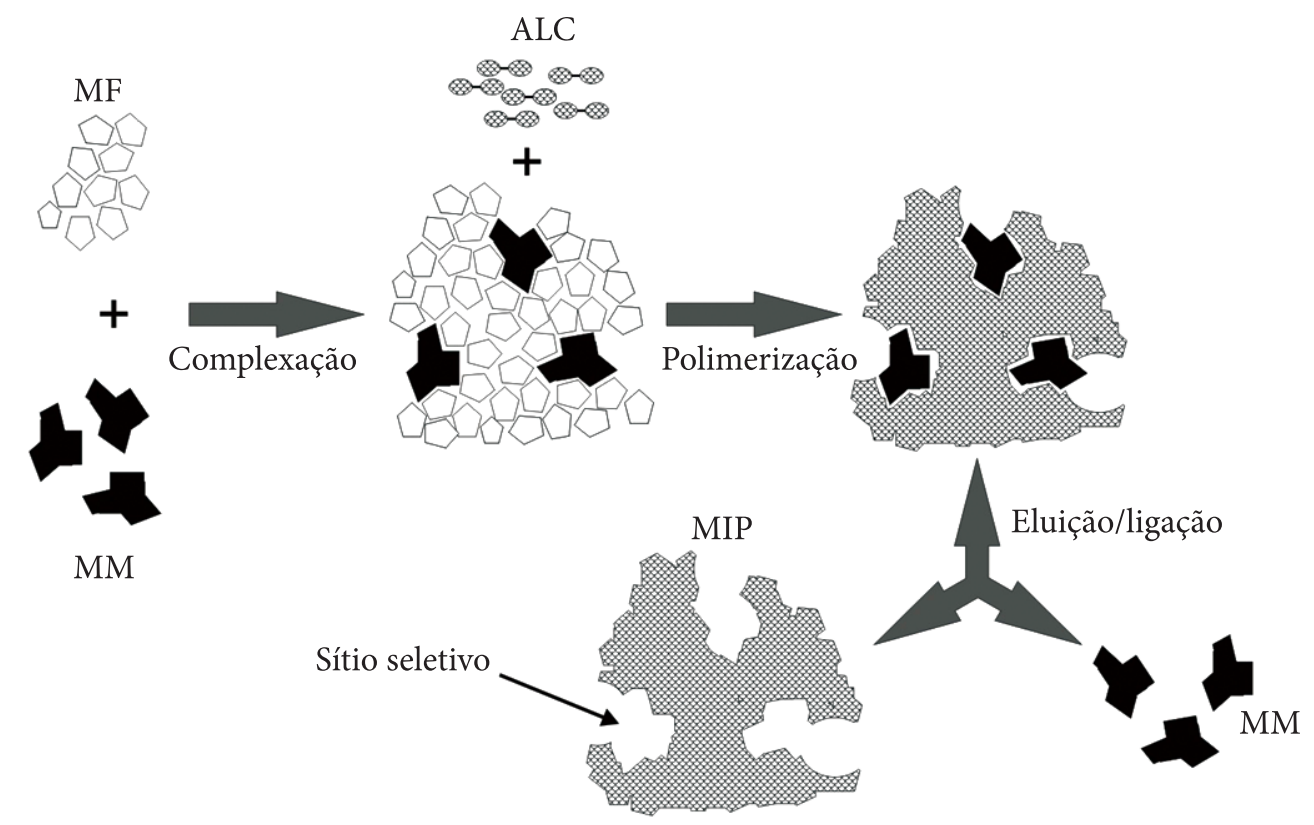

Figura 1 Esquema genérico da síntese de MIP: MF: monômero funcional; MM: molécula modelo; e ALC: agente de ligação cruzada. 
relata a extração de seis clorotiazinas em amostras de água subterrânea e sedimento, utilizando um polímero impresso com terbutilazina ${ }^{[35,36]}$.

O uso de MIPs para análise de amostras de alimento ainda representa uma pequena fração em número de publicações quando comparado a análises de amostras biológicas e ambientais. Entretanto, espera-se que haja um aumento significativo dessa aplicação em virtude das já bem comentadas vantagens da utilização dos MIPs em amostras complexas. Contudo, cabe destacar alguns procedimentos de extração em fase sólida molecularmente impressa nesse tipo de matriz, incluindo: análise de praguicidas, fármacos, compostos fenólicos e toxinas em matrizes como leite, vinho, cereais, frutas, frutos do mar, entre outros $^{[37-42]}$.

\section{Metodologias de síntese}

Os processos de síntese dos MIPs mais empregados atualmente são a polimerização por sol-gel e aqueles em que a polimerização ocorre a partir de radicais livres. $O$ processo sol-gel tem como atrativo a combinação de compostos orgânicos e inorgânicos dando origem a uma nova classe de materiais com diferentes propriedades. Sua rota de síntese é baseada em uma transição do sistema sol (dispersão de partículas coloidais estáveis em um fluído) para um sistema gel (sistema formado por estruturas rígidas de partículas coloidais ou cadeias poliméricas). Esta metodologia de síntese vem se popularizando e tem sido empregada em polímeros para análise de amostras ambientais, fluidos biológicos e alimentos através de diferentes técnicas de extração ${ }^{[43]}$.

A formação de compostos tridimensionais pelo processo sol-gel se dá através de precursores que podem ser moléculas trifuncionais, como $\mathrm{MeSi}(\mathrm{OR})_{3}$ ou tetrafuncionais, como
$\mathrm{Si}(\mathrm{OR})_{4}$, que em presença de umidade, oriunda do ar ou da própria água, sofrem uma reação de hidrólise, gerando grupos silanóis. Em seguida, ocorrem reações de condensação destes grupos silanóis com alcóxidos (-SiOR) ou outros silanóis $(-\mathrm{SiOH})$, liberando álcool $(\mathrm{R}-\mathrm{OH})$ ou $\mathrm{H}_{2} \mathrm{O}$, respectivamente. Estas reações podem ser aceleradas por catalisadores à base de sais de alquil estanho, por exemplo. Neste processo, quando o precursor do sol-gel é um sal, a reação ocorre entre ele e o solvente, que geralmente é polar. Quando o precursor é um alcóxido metálico, é acrescentado um MF ao processo, dando especificidade aos sítios de ligação. O tetraetilortossilicato (TEOS) ${ }^{[44-47]}$ merece destaque por ser o reagente mais utilizado na síntese de MIPs pelo processo sol-gel ${ }^{[43,48,49]}$.

A síntese a partir de radicais livres, sem dúvida, é a mais utilizada para a obtenção dos MIPs. Neste sentido, há três diferentes abordagens: a covalente, a não covalente e a semicovalente. Na primeira abordagem, ocorrem ligações covalentes reversíveis entre a MM e o MF. A retirada da MM ocorre pela clivagem das ligações correspondentes. A forte ligação entre a MM e o MF é a principal vantagem desta forma de síntese, o que garante uma maior seletividade ao material, porém, dificulta o processo de eluição dos analitos, sendo necessário, em muitos casos, procedimentos drásticos de hidrólise ${ }^{[36]}$.

A síntese não covalente ocorre a partir da formação de interações relativamente fracas (ligações de hidrogênio, interações eletrostáticas etc.) entre a MM e o MF. Ela oferece a possibilidade de aplicação para analitos que pertençam a uma mesma classe e, devido à facilidade de eluição dos compostos de interesse, tem sido extensamente utilizada para o preparo de amostras. Contudo, os polímeros obtidos oferecem uma menor seletividade quando comparados àqueles que foram obtidos pela síntese covalente ${ }^{[50]}$. 
Buscando as vantagens que essas duas abordagens oferecem, foi criada a síntese semicovalente, que estabelece que o processo de polimerização seja mediado por ligações covalentes, garantindo maior seletividade, enquanto as demais interações, durante a utilização do material, sejam estabelecidas por ligações não covalentes, facilitando assim o processo de eluição ${ }^{[51]}$.

A abordagem não covalente é a mais empregada quando falamos de MIPs utilizados no preparo de amostras. A síntese acontece da junção de alguns componentes como a MM, o MF, o agente de ligação cruzada, o iniciador radicalar e o solvente porogênico. A escolha desses reagentes deve ser bem estudada, pois a qualidade do produto final é determinante para que haja seletividade. Ao se definir a molécula modelo e o monômero funcional, é necessário observar e estimar as possíveis interações intermoleculares que ocorrerão entre eles, a fim de que estas sejam favoráveis à retenção seletiva do analito. Relatos recentes apontam o ácido metacrílico $(\mathrm{MAA})^{[52-57]}$ e a 4-vinilpiridina (4-VP) ${ }^{[55,58]}$ como os MFs mais utilizados. Os agentes de ligação cruzada (ALC) são os responsáveis pelo caráter tridimensional dos MIPs. Os mais utilizados são o divinilbenzeno (DVB) ${ }^{[54]}$ e o etilenoglicol dimetacrilato (EGDMA) ${ }^{[52-55]}$. O iniciador radicalar é o responsável pelo início da polimerização. Esta pode ocorrer por um processo termoquímico e/ou fotoquímico. O mais empregado é o azoisobutironitrila (AIBN) $)^{[52-58]}$. Com relação ao solvente utilizado, é importante lembrar que ele deve solubilizar os reagentes sem que haja reação entre eles. Neste contexto, destaque para o tolueno, metanol e clorofórmio, que são os mais utilizados $^{[43]}$.

Devido ao baixo reconhecimento molecular em meio aquoso, diferentes estratégias são utilizadas para que materiais sintetizados com solventes porogênicos orgânicos apresentem boa recuperação durante sua utilização em matrizes aquosas. Dessa forma, são apresentadas três metodologias de síntese: in bulk, por precipitação e por suspensão ${ }^{[43]}$.

A primeira e mais utilizada é a polimerização in bulk. Nesta metodologia, os reagentes são colocados em uma ampola de vidro que é lacrada, formando no final da síntese um monólito que vai ser macerado, tamisado e lavado para a retirada da MM. Devido à necessidade de maceração, as partículas finais apresentam tamanho homogêneo, porém, formato irregular ${ }^{[43]}$. Relatos na literatura apresentam a utilização deste tipo de polimerização para a obtenção de MIPs empregados em diversas técnicas de preparo de amostras, tais como SPE, SPME, entre outras $^{[52,53,59]}$.

Outro tipo de síntese radicalar é a que ocorre por precipitação. Ela se diferencia da síntese in bulk pelo grande volume do solvente porogênico empregado. O procedimento ocorre sob agitação e os polímeros apresentam tamanhos e formatos mais uniformes ${ }^{[43]}$. Algumas variantes da síntese por precipitação têm sido empregadas, como, por exemplo, a polimerização controlada (RAFT). Como vantagem, ela apresenta a possibilidade de controle do início, término e da velocidade da síntese por meio do uso de um controlador ${ }^{[55]}$. Um MIP para atrazina foi sintetizado pelo processo de RAFT utilizando nanopartículas de sílica, MAA, EGDMA, AIBN, acetonitrila e o agente controlador. $\mathrm{O}$ material apresentou morfologia mais uniforme e uma maior capacidade de ligação quando comparado aos MIPs obtidos por precipitação tradicional ${ }^{[54]}$. Já em outro trabalho, um MIP, também obtido pelo processo de RAFT, foi sintetizado empregando-se um monômero hidrofílico, visando sua utilização em meio aquoso. Neste estudo, o herbicida ácido 2,4 diclorofenoxiacético foi usado como MM. Os demais reagentes foram 4-VP, EGDMA, AIBN, metanol 
e o controlador cumil ditiobenzoato (CDB). O precipitado obtido foi lavado e a síntese foi reiniciada acrescentando-se hidroxietil metacrilato (HEMA) e AIBN. Houve formação da camada hidrofílica desejada no material, possibilitando sua utilização em matrizes aquosas, sem perda de reconhecimento molecular ${ }^{[55]}$.

Já na síntese por suspensão, a reação polimérica ocorre dentro de gotas do monômero dispersas em uma fase contínua. Essas gotas ou micelas são estabilizadas por um surfactante colocado nesse meio reacional em que ocorre a polimerização ${ }^{[43,48]}$. Como a fase contínua para a suspensão geralmente é água, existe a tendência do enfraquecimento das ligações eletrostáticas e ligações de hidrogênio que ocorrem entre a molécula modelo e o monômero funcional. Para solucionar este inconveniente, já existem relatos de suspensões que substituem a água por outros reagentes na busca de um melhor reconhecimento da molécula ${ }^{[43,48]}$. O formato e o tamanho do MIP obtido ao final da síntese vão depender do tamanho da micela formada. Assim, a síntese de um MIP para análise de propranolol em plasma foi proposta utilizando-se MAA, trimetilpropano trimetacrilato (TRIM), AIBN e acetonitrila. Essa mistura foi colocada num frasco com óleo mineral. Posteriormente, ela foi agitada em dispersor automático e a polimerização ocorreu em um reator. Os pequenos monólitos formados foram pulverizados e tamisados para utilização ${ }^{[56]}$. Para análise de anti-histamínicos em água, um procedimento similar foi adotado por Walsh et al., tendo como único diferencial o acréscimo de água no meio reacional ${ }^{[57]}$. A síntese por suspensão também pode ser realizada por intermédio de polímeros com granulometria conhecida, inicialmente colocados nas gotículas da suspensão. Os demais reagentes de síntese são acrescidos passo a passo até o início da polimerização ${ }^{[60]}$. Este processo foi empre- gado na síntese de um polímero de impressão molecular restrito à ligação com macromoléculas (RAM-MIP) para herbicidas. Para isto, uma dispersão de dibutilftalato, dodecil sulfato de sódio e óleo foi preparada. Partículas de poliestireno foram dispersas neste meio. Num segundo momento, 2,2-azobis(2,4-dimetilvaleronitrila), tolueno e álcool polivinílico foram integrados ao meio reacional. Por fim, houve a adição da atrazina (MM), MAA e EGDMA. Para evitar os problemas citados anteriormente com relação à utilização de água no meio reacional, os autores propuseram o recobrimento do MIP por uma camada protetora. Assim, glicidil monometacrilato (GMMA), glicidil dimetacrilato (GDMA) e peróxido dissulfato de potássio, foram acrescentados ao meio reacional, finalizando a síntese. O material obtido apresentou uma morfologia homogênea e, depois de lavado, mostrou-se apto para utilização como fase estacionária em cromatografia líquida ${ }^{[60]}$.

Finalmente, pode-se constatar que uma metodologia de síntese deve ser selecionada com base nas aplicações dos respectivos polímeros e levando em conta o tipo e a técnica de preparo de $\operatorname{amostras}^{[61]}$.

\section{Emprego de MIP no preparo de amostras}

\subsection{Extração em fase sólida molecularmente impressa - MISPE}

Basicamente, duas configurações de MISPE têm sido empregadas para o preparo de amostras, a off-line e a on-line (Figura 2). Os protocolos off-line são bem semelhantes aos procedimentos de SPE convencionais. Tipicamente, uma pequena quantidade de MIP (15-500 mg em média) é empacotada em cartuchos de polietileno ou polipropileno (Figura 2) . Em seguida, realizam-se as 
etapas de condicionamento, carregamento com amostra, lavagem (quando necessário) e eluição. Depois da extração, o eluato resultante é então introduzido no sistema analítico ${ }^{[36]}$.

A principal vantagem que os MIPs têm a oferecer para a SPE é uma significativa melhora na seletividade da extração, uma vez que este sorvente fornece uma maior retenção para o analito de interesse do que para o restante dos compostos também presentes na amostra. Muitas vezes os MIPs também podem extrair estruturas estreitamente relacionadas à MM (geralmente compostos da mesma classe) através de um efeito conhecido como seletividade cruzada, o que permite a obtenção de extratos limpos, facilitando assim a quantificação dos analitos de interesse ${ }^{[11]}$.

Nos últimos anos, tem-se verificado um enorme desenvolvimento de métodos que utilizam a MISPE off-line para uma grande variedade de analitos em diversos tipos de amostras (biológicas, ambientais e de alimentos). Javanbakht et al. desenvolveram um método que utiliza a MISPE como técnica de limpeza e pré-concentração combinada com a cromatografia líquida de alta eficiência com detector ultravioleta (HPLC-UV) para análise de tramadol a partir de amostras de plasma e urina. Neste
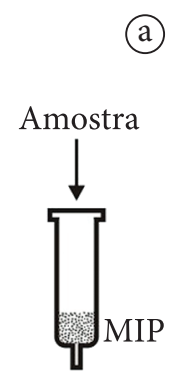

(b)

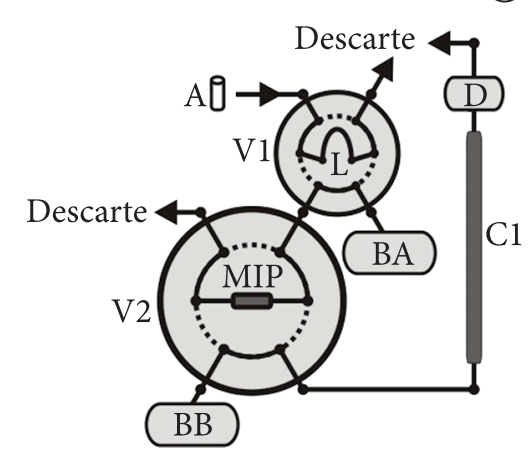

Figura 2 Cartucho de extração em fase sólida usando MIP (a) e sistema on-line de extração em fase sólida usando MIP (b). V1 e V2 são válvulas de 6 vias, $A$ é amostra, $B A$ e $B B$ são bombas, $C 1$ é coluna analítica e L é loop de amostragem. estudo, o MIP foi preparado utilizando-se MAA, EGDMA, clorofórmio como solvente porogênico e tramadol como MM. O polímero impresso foi empregado como sorvente para a SPE. Vários parâmetros que afetam a eficiência da extração foram avaliados e as condições ótimas de extração foram otimizadas. A seletividade do MIP foi avaliada através de testes com várias substâncias de estrutura química semelhantes ao tramadol. Os autores conseguiram obter baixos limites de detecção e quantificação, bem como níveis de recuperação satisfatórios ${ }^{[27]}$.

Em outro estudo, um MIP com seletividade para metocarbamol foi planejado computacionalmente através de estudos de modelagem molecular com base na síntese não covalente por Gholivand \& Khodadadian. A biblioteca virtual contava com 18 tipos de MFs diferentes, com os quais foi possível simular a síntese, investigar as possíveis interações entre os monômeros, a MM e o solvente ideal. Com base nos resultados computacionais, o ácido acrílico (AA) e o tetra-hidrofurano foram considerados as melhores opções de escolha como MF e solvente porogênico, respectivamente. O MIP foi então sintetizado pelo método de precipitação e utilizado como adsorvente seletivo para a SPE. Depois da extração, a determinação do metocarbamol em amostras de plasma pôde ser efetuada por voltametria de pulso diferencial (DVP) e HPLC-UV. A determinação por DVP foi mais sensível, mas ambas as técnicas apresentaram precisão e exatidão equivalentes ${ }^{[28]}$.

Um método utilizando MISPE foi desenvolvido por Yang et al. para análise de níveis de nicotina em cabelo de fumantes e não fumantes por HPLC-UV. O MIP foi sintetizado utilizando-se nicotina como MM e MAA como MF. Este método apresentou boa seletividade e sensibilidade para a nicotina, com limites de detecção e quantificação de $0,2 \mathrm{ng} \mathrm{mL}^{-1}$ e $0,5 \mathrm{ng} \mathrm{mL}^{-1}$, res- 
pectivamente. O método foi linear para a faixa de 0,5-80,0 ng mL ${ }^{-1}$, com coeficiente de determinação de 0,987. Este ensaio mostrou-se adequado para análise da exposição ao tabaco, com boa exatidão e precisão ${ }^{[29]}$.

Já Vitor et al. avaliaram a exposição ao tabaco a partir de um método constituído de MISPE e HPLC acoplado a um detector de arranjo de diodos (DAD) para análise de cotinina (um metabólito da nicotina) em saliva. As variáveis da extração tais como a quantidade de amostra, condições de condicionamento, lavagem e eluição foram otimizadas. O método mostrou-se linear, com boa precisão, exatidão, robustez e baixos limites de detecção e quantificação. $\mathrm{O}$ estudo resultou num método confiável para a determinação de cotinina em saliva, mostrando ser um importante instrumento para acompanhar a exposição à fumaça do cigarro $^{[26]}$.

Um estudo realizado por Soleimani et al. descreveu a síntese de um MIP utilizando albumina bovina como molécula modelo, fato este bem interessante, considerando que a albumina é uma proteína, molécula grande e complexa, o que poderia comprometer a seletividade do material. A MISPE foi utilizada para a extração de albumina bovina em amostras de soro sanguíneo, urina, soro de leite e leite. O material foi caracterizado por espectroscopia de infravermelho com transformada de Fourier (FT-IR) e análise termogravimétrica. A capacidade adsortiva máxima do polímero foi de $24 \mathrm{mg} \mathrm{g}^{-1}$ de MIP. A faixa linear obtida variou de $20-200 \mathrm{mg} \mathrm{L}^{-1}$ de albumina bovina e, apesar de não ser usual a utilização de MIPs para extração de substâncias como proteínas, o método mostrou-se preciso e exato para este tipo de análise com valores de recuperação em torno de $80 \%$ para as amostras $\operatorname{avaliadas}^{[62]}$.
Vieira et al. desenvolveram MIPs para a extração de ácido trans, transmucônico (AttM), um metabólito do benzeno, a partir de amostras de urina, seguido por análise com HPLC-UV ${ }^{[63]} \mathrm{e}$ cromatografia gasosa-espectrometria de massas (GC-MS) ${ }^{[64]}$. A 4-vinilpiridina foi utilizada para a síntese por ser um monômero de características básicas. Ambos os métodos foram lineares, precisos e exatos com limites de quantificação inferiores ao limite proposto pela American Conference of Governmental Industrial Hygienists (ACGIH) (0,5 $\mathrm{mg} \mathrm{g}^{-1}$ de creatinina), que sugere o AttM como indicador biológico de exposição ao benzeno. Vale ressaltar que foi possível reaproveitar o mesmo cartucho de MIP por cerca de 100 ciclos. Ambos os métodos mostraram eficiência equivalente ao procedimento baseado em extração por troca iônica e podem ser alternativas interessantes para análise de AttM em laboratórios de rotina ${ }^{[63,64]}$.

Buscando inovar e melhorar a técnica, Khorrami e Rashidpur propuseram um novo design para cartuchos de SPE, utilizando MIP como sorvente. $\mathrm{O}$ aparelho é constituído de um tubo afunilado modificado para permitir a extração simultânea em uma fase orgânica e outra sólida. Para avaliar o desempenho do método proposto, este foi empregado para análise de teofilina em amostras de soro sanguíneo. Assim, uma quantidade adequada do MIP para teofilina foi acondicionado no fundo do tubo. Certa quantidade de solvente foi pipetada até que o MIP estivesse completamente entumecido. Em seguida, um frit de polietileno foi posicionado entre dois anéis de teflon a fim de segurar as partículas de MIP abaixo do nível da camada orgânica. Depois desta etapa, uma solução de amostra aquosa foi colocada sobre a fase orgânica e a tampa foi fechada. Depois da conclusão da extração, as fases orgânica e aquosa foram removidas e o analito adsorvido no MIP foi eluído com um 
solvente mais polar. Os parâmetros de extração foram otimizados a fim de melhorar os níveis de recuperação e os extratos foram analisados por HPLC-UV. O método mostrou-se adequado, seletivo e com bons níveis de recuperação para teofilina em plasma (79\%-83\%). Como desvantagem, ressalta-se que a vida útil do cartucho foi de apenas 10 ciclos de extração ${ }^{[65]}$.

Em uma análise ambiental, Dai et al. sintetizaram um polímero por precipitação para análise de diclofenaco em amostras de água. $\mathrm{O}$ MIP apresentou excelente afinidade para esse analito, com uma capacidade máxima adsortiva de 324,8 $\mathrm{mg} \mathrm{g}^{-1}$ de material. As análises foram feitas por HPLC-DAD. Vários parâmetros da extração foram otimizados e excelentes níveis de recuperação foram obtidos tanto para águas residuais e águas de rios, como para água de abastecimento (ca. 95\%). Depois de testes de estabilidade do material, foi possível comprovar que o seu desempenho manteve-se estável por ca. de 30 ciclos de extração ${ }^{[32]}$.

Para análise simultânea de seis diferentes piretroides em águas utilizadas para cultura de frutos do mar, foram sintetizados dois diferentes MIPs, um utilizando a deltametrina como MM e, o outro, a cipermetrina. Assim, Shi et al. realizaram estudos para comparar o desempenho de ambos e dos polímeros não impressos (NIPs). Os melhores resultados foram obtidos quando o polímero que utilizou a cipermetrina como MM foi empregado na MISPE, com recuperações de 86,4\%-96\%. Depois da extração, as análises foram feitas por meio de cromatografia gasosa acoplada a um detector de captura de elétrons $(\mathrm{GC}-\mathrm{ECD})^{[66]}$.

Em alguns casos, os MIPS não são capazes de reconhecer seletivamente moléculas pequenas com um número limitado de grupos funcionais. Neste trabalho, um novo método foi proposto por El-Sheikh et al. para melhorar a capacidade de reconhecimento do 2-clorofenol (2-CP) pelo polímero e, consequentemente, melhorar o processo de MISPE. Isto foi conseguido através da derivatização do 2-CP com 4-aminoantipirina (4-AAP) para ampliar e inserir sítios de reconhecimento na molécula. Para estudar a eficiência do procedimento, foram sintetizados dois polímeros, um utilizando o 2-CP sem alterações como MM e o outro usando o 2-CP derivatizado. A seletividade e os limites de detecção deixaram a desejar no primeiro caso. Já o segundo demonstrou elevada capacidade de reconhecimento e limite de detecção bem inferior. $\mathrm{O}$ método foi capaz de detectar a presença de 2-CP em amostras de água ambientais com bons níveis de recuperação $^{[31]}$.

Para realizar um estudo acerca da presença de parabenos em sedimentos marinhos, uma metodologia analítica incorporando MISPE foi desenvolvida por Nunes et al. Quatro polímeros diferentes foram preparados combinando acetonitrila e tolueno como solventes porogênicos, 4-VP e MAA como MFs e benzilparabeno como MM. Embora todos os polímeros fossem capazes de reconhecer os analitos de interesse (metil, etil, propil, butil, isopropil, isobutil e benzilparabeno), o MIP preparado com tolueno e MAA apresentou melhor desempenho quando empregado na MISPE. A análise foi realizada por HPLC-UV e cromatografia líquida acoplada à espectrometria de massas (triplo quadrupolo) $(\mathrm{LC}-\mathrm{MS} / \mathrm{MS})^{[33]}$.

Barros, Martins e Rath desenvolveram um MIP para análise de fenitrotion (FNT) em tomates, levando em consideração a ampla utilização desse praguicida nesses tipos de cultura. A análise foi baseada em MISPE seguida por HPLC-DAD. Usando o FNT como MM, o polímero foi sintetizado empregando-se MAA, EGDMA e tolueno. A fim de conhecer o meio que melhor promovesse o reconhecimento molecular do FNT pelo 
MIP, estudos de adsorção foram realizados em diferentes meios contendo acetonitrila e tolueno. Além do FNT, três compostos estruturalmente relacionados foram usados para avaliar a seletividade do material, que mostrou maior afinidade pela MM. A eficiência da extração foi de $96 \%$ e os limites de detecção e quantificação foram de 0,05 e $0,13 \mu \mathrm{g} \mathrm{g}^{-1}$. O método desenvolvido apresentou precisão e exatidão adequadas ${ }^{[67]}$.

A análise de substâncias em amostras de alimentos que contenham lipídeos apresenta algumas limitações tais como pré-tratamentos que envolvem, entre outros procedimentos, reações de saponificação e pré-extração com solventes orgânicos. No intuito de superar este tipo de problema, Puoci et al. propuseram um método baseado em MISPE para a determinação de colesterol em amostras de queijo calabrês. A possibilidade de se obter o reconhecimento seletivo do colesterol sem interações hidrofóbicas inespecíficas é a principal vantagem desse material. Outra vantagem importante é a análise direta do eluato por HPLC-UV sem qualquer tipo de tratamento. A avaliação da seletividade foi testada comparando-se a capacidade adsortiva do MIP para colesterol em relação a outras duas moléculas estruturalmente semelhantes, a progesterona e a hidrocortisona. Boas recuperações foram obtidas para o método que se mostrou promissor para análise de colesterol em amostras de alimentos $^{[68]}$.

Um novo método empregando-se MISPE e LC-MS/MS foi desenvolvido por She et al. para análise de herbicidas pertencentes à classe das sulfonilureias (clorsulfuron (CS), monosulfuron (MNS) e metiltifensulfuron (TFM)) em amostras de milho. O MIP seletivo para estes compostos foi sintetizado por precipitação usando o clorsulfuron como MM, o 2-(dietilamino) etilmetacrilato (DEAMA) como MF e o TRIM como reagente de ligação cruzada. Os parâ- metros ideais de extração foram otimizados de modo a obter os melhores níveis de recuperação, sendo estes em torno de 75\%-110\%. Baixos limites de detecção foram alcançados, bem como boa linearidade, exatidão e precisão, mostrando que o método é adequado para análise de sulfonilureias em cereais ${ }^{[38]}$.

Uma sílica gel amino-funcionalizada impressa foi sintetizada por Jiang et al. para análise de dietilestilbestrol (DES), um análogo estrutural sintético do estrógeno, em amostras de peixe. O material foi obtido através da combinação das técnicas de impressão molecular com o processo de sol-gel. A sílica gel ativada foi utilizada como suporte para a síntese dos polímeros impresso e não impresso. Comparado com o material não impresso, o MIP mostrou elevada capacidade de adsorção, seletividade significativamente maior e rápida cinética de ligação para o DES. A capacidade máxima adsortiva do polímero impresso foi de $62,58 \mathrm{mg} \mathrm{g}^{-1}$ de material, enquanto que para o não impresso foi de apenas $19,89 \mathrm{mg} \mathrm{g}^{-1}$ de material. Os parâmetros cinéticos de adsorção mostraram-se bastante rápidos, de modo que o equilíbrio foi alcançado dentro de 10 minutos. A análise foi realizada por HPLC-UV e mostrou-se adequada para a determinação de DES em amostras de alimentos ${ }^{[69]}$.

Com as vantagens de se evitar a manipulação da amostra entre as etapas de pré-concentração e análise, reduzindo, portanto, riscos de perda de analitos e contaminação e, melhorando a exatidão e a reprodutibilidade, a automação do processo de MISPE pode ainda reduzir muito o tempo dispensado para o preparo da amostra ${ }^{[70]}$. A este acoplamento do preparo de amostras em linha com a técnica cromatográfica de análise dá-se o nome de MISPE on-line (Figura 2).

A ciência ambiental vem despertando cada vez mais interesse em relação à análise de contaminantes das mais variadas naturezas, entre eles 
disruptores endócrinos. Xu et al. relataram a síntese de microesferas de sílica gel impressas molecularmente como material altamente seletivo sintetizado por uma técnica de impressão molecular de superfície, combinada com um processo sol-gel, utilizando estrona como MM. Este material foi aplicado para separação e determinação de traços deste hormônio em amostras ambientais através da extração em fase sólida molecularmente impressa acoplada a HPLC-UV ${ }^{[71]}$.

Outra técnica associada à MISPE para análise de amostras ambientais de água foi um sistema de quimioluminescência acoplado com injeção em fluxo para determinação de 2,4-diclorofenol, desenvolvida por Feng et al. O polímero para este composto foi preparado através de técnicas não covalentes de impressão molecular, utilizando-se 4-VP e EGDMA como monômero e ALC, respectivamente. O composto 2,4-diclorofenol foi seletivamente adsorvido pelo MIP e, então, determinado pelo efeito aumentado sobre a reação de quimioluminescência entre permanganato de potássio e luminol ${ }^{[72]}$.

Figueiredo et al. descreveram o preparo e avaliação de um MIP para a pré-concentração de catecol em amostras ambientais e de refrigerantes através de polimerização in bulk. A determinação espectrofotométrica empregada na quantificação foi baseada na descolorimetria oriunda da redução de $\mathrm{Mn}$ (VII) a $\mathrm{Mn}$ (II) pelo catecol em meio ácido. A MISPE foi o único elemento de seletividade visto que a reação de oxirredução entre catecol e Mn(VII) é sensível a diversos compostos. Os autores obtiveram bons resultados com uma faixa analítica de 3,0 a $100 \mu \mathrm{mol} \mathrm{L}^{-1}(\mathrm{r}>0,999)$ e um limite

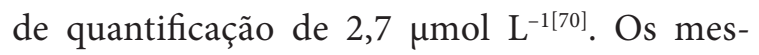
mos autores empregaram a associação MISPE e espectrofotometria na análises de nicotina em amostras biológicas. O método se baseou na redução de $\mathrm{Mn}(\mathrm{VII})$ a $\mathrm{Mn}(\mathrm{VI})$, promovida pela nicotina, em meio alcalino. Como se trata de uma reação inespecífica, a seletividade obtida foi atribuída ao MIP. A exatidão do método foi avaliada comparando-se a técnica de injeção em fluxo - MISPE com um método de cromatografia líquida de alta eficiência. Não foram observadas diferenças significativas, considerando-se um intervalo de confiança de 95\%. É interessante ressaltar os bons resultados de frequência analítica $\left(11 \mathrm{~h}^{-1}\right)$ e limite de quantificação $\left(1,1 \mu \mathrm{mol} \mathrm{L}{ }^{-1}\right)$ do método proposto quando comparados com os mesmos parâmetros para o método por HPLC $\left.\left(2 \mathrm{~h}^{-1} \text { e } 3,0 \mu \mathrm{mol} \mathrm{L}\right)^{-1}\right)^{[70]}$.

Em outro estudo, Figueiredo et al. quantificaram seis benzodiazepínicos (medazepam, nitrazepam, diazepam, clordiazepóxido, clonazepam e midazolam) em plasma humano através de um sistema que utiliza uma sonda contendo MIP como material de empacotamento, acoplada a uma fonte de eletrospray (ESI) e a um espectrômetro de massas sem pré-separação. Para a síntese do MIP, o diazepam foi empregado como MM, MAA como MF, EGDMA como ALC e AIBN como iniciador radicalar. A extração seletiva de moléculas-alvo de uma mesma classe diminuiu o fenômeno de supressão iônica e os analitos foram quantificados em um curto intervalo de tempo. O método proposto ainda apresentou bons resultados em relação à precisão, exatidão e limite de quantificação ${ }^{[73]}$.

Yan, Qiao e Row propuseram colunas monolíticas impressas sintetizadas por polimerização inicial térmica in situ, utilizando norfloxacina como MM, 2-hidroxietilmetacrilato como monômero e metanol - água como solvente porogênico para quantificação de enrofloxacina e ciprofloxacina em urina de animais. A enrofloxacina é uma fluoroquinolona muito utilizada na medicina veterinária e, em várias espécies, pode ser biotransformada em ciprofloxacina, seu metabólito primário. O monólito 
obtido apresentou alta afinidade por enrofloxacina e ciprofloxacina em meio ambiente aquático e foi aplicado com sucesso como sorvente especial para extração seletiva on-line de enrofloxacina e ciprofloxacina em amostras de urina. Estas amostras foram centrifugadas e injetadas diretamente no sistema cromatográfico sem qualquer outro pré-tratamento. $\mathrm{O}$ método apresentou boa linearidade $\left(0,05-200 \mathrm{mg} \mathrm{L}^{-1}\right)$, valores de RSD menores que 3,1\%, limite de detecção de $0,01 \mathrm{mg} \mathrm{L}^{-1}$ e recuperações maiores que $87 \% \mathrm{em}$ diferentes concentrações ${ }^{[74]}$.

Além das aplicações ambientais e biológicas, a técnica de MISPE é muito utilizada na área de alimentos, principalmente para determinação de resíduos das mais variadas naturezas, que normalmente estão presentes em concentrações muito baixas. Com o objetivo de concentrar e analisar estrógenos em leite, Zhao et al. sintetizaram, por irradiação ultrassônica, um polímero de impressão molecular (MIP) com atapulgita como matriz, $\beta$-naftol como MM, acriloil- $\beta$-ciclodextrina como MF e N, N-metilenobiacrilamida como ALC. Em comparação com os polímeros preparados pelas fontes de aquecimento tradicionais, este apresentou melhor seletividade e cinética de adsorção mais rápida para estriol, estradiol, estrona e dietiestibestrol. A coluna de MIP foi preparada para acoplamento on-line simultâneo da SPE com o sistema de HPLC, e o método desenvolvido apresentou limites de detecção na faixa de $1-8 \mathrm{ng} \mathrm{g}^{-1[75]}$.

Oliveira et al. propuseram uma metodologia que une a técnica de MISPE com um sistema BI-LOV (bead injection - lab on valve) para determinação de riboflavina em amostras de alimentos. A configuração do módulo lab-on-valve compreende uma estrutura monolítica com microcanais e permite a injeção e o transporte de suspensões esféricas de maneira completa- mente automatizada. Obteve-se alta precisão ao manipular suspensões contendo partículas de MIP de formato irregular, permitindo o uso de MIP comercial como sorvente renovável. Utilizando-se este método on-line, foi possível extrair e quantificar riboflavina de amostras de alimentos em uma faixa de 0,450 a 5,00 $\mathrm{mg} \mathrm{L}^{-1}$ depois do processamento de $1000 \mu \mathrm{L}$ de amostra (leite infantil, extrato de fígado de porco e bebida energética) sem nenhum outro tratamento prévio $^{[76]}$.

Zhang et al. propuseram um novo material de estrutura core-shell cujo núcleo core é uma estrutura de nanotubos de carbono de paredes múltiplas e, a fase shell é uma camada de MIP polimerizada sobre a superfície dos nanotubos. Este material foi preparado pela técnica de impressão em superfície em combinação com a tecnologia sol-gel. Este foi utilizado como sorvente para análise de traços do corante Sudan IV em amostras de pimenta chilli em pó, através da extração em fase sólida on-line acoplada à HPLC. O material se mostrou bastante eficiente, apresentando elevado fator de enriquecimento para determinação de Sudan IV em amostras reais ${ }^{[77]}$.

Ainda na área de alimentos, Xu, Fang e Wang prepararam um polímero impresso altamente seletivo pela técnica de polimerização in bulk mediada por líquido iônico à temperatura ambiente, utilizando diclorvós como MM, MAA como MF e trimetilpropano trimetacrilato como ALC. Este material foi empregado como sorvente para extração em fase sólida e a técnica de pré-tratamento de amostra foi acoplada a HPLC-UV para determinação de resíduos de diclorvós em alimentos, gerando bons resultados, como limite de detecção da ordem de ng $\mathrm{L}^{-1}$ para este praguicida ${ }^{[78]}$.

Em alguns trabalhos, são relatadas combinações das configurações on-line e off-line de MISPE. Dong et al. propuseram a utilização da 
técnica de MISPE para determinação de resíduos de monossulfuron em amostras de solo. Foram estudados procedimentos off-line e on-line. $\mathrm{O}$ procedimento off-line foi utilizado para avaliar as diferenças entre as soluções de lavagem e eluição. A técnica on-line, por sua vez, foi empregada para otimizar as condições de SPE e para o processo de clean-up da amostra ${ }^{[34]}$.

Os MIPs também vêm sendo utilizados de forma bem sucedida como sorventes altamente seletivos para a determinação de compostos benzimidazólicos em meio orgânico. Com este propósito, Cacho, Turiel e Pérez-Conde propuseram a síntese de um MIP para compostos benzimidazólicos através de polimerização por precipitação, utilizando tiabendazol, MAA, EGDMA, DVB, acetonitrila e tolueno. O polímero de DVB apresentou capacidade de receber maiores volumes de amostra e foi, portanto, selecionado para os próximos testes. Este MIP se mostrou capaz de reter não apenas a molécula-modelo, mas também outros compostos benzimidazólicos (albendazol, benomil, carbendazim, fembendazol, flubendazol e fuberidazol). Tal material foi utilizado em um procedimento de pré-concentração on-line e esta metodologia se mostrou aplicável para propósitos de varredura (verificar apenas a presença dos analitos na matriz), enquanto a identificação e a quantificação de cada composto deveriam ser realizadas através da pré-concentração off-line em cartuchos contendo MIP seguida de análise por HPLC-DAD. O método de MISPE proposto foi aplicado para a pré-concentração off-line e todos os compostos benzimidazólicos puderam ser quantitativamente recuperados. Em paralelo, as amostras passaram por procedimento de pré-concentração em discos C18 e os cromatogramas mostraram linhas de base com mais ruído, além de várias espécies terem interferido na determinação de fembendazol. Observando-se todos os resultados obtidos, a utilização de MIP como sorvente seletivo para determinação multirresidual de compostos benzimidazólicos em águas se mostrou bastante vantajosa e tanto o procedimento de pré-concentração on-line quanto o off-line apresentaram limites de detecção bem abaixo dos níveis de concentração máxima permitidos pela legislação ${ }^{[79]}$.

\subsection{Extração sortiva em barra de agitação molecularmente impressa- MISBSE}

$\mathrm{Na}$ extração sortiva em barra de agitação (SBSE), uma barra magnética revestida de polidimetilsiloxano é colocada diretamente na amostra e agitada até que o equilíbrio de partição entre os analitos e o sorvente seja atingido. Depois da extração, os analitos podem ser quantitativamente introduzidos no sistema analítico por dessorção térmica ou líquida ${ }^{[80]}$. Um dos fatores que interfere no processo de extração e pode ser otimizado nos procedimentos de SBSE é o revestimento da barra de agitação.

Zhu e Zhu descreveram o preparo de barras de agitação revestidas por um filme molecularmente impresso de $160 \mu \mathrm{m}$, formado a partir de uma solução do polímero Nylon-6 em ácido fórmico e observaram o desempenho deste material para separação enantiosseletiva de aminoácidos. A barra de agitação revestida pelo polímero Nylon-6 impresso com L-glutamina foi preparada através de um método de inversão de fase. Soluções de Nylon-6 e L-glutamina foram misturadas em ácido fórmico e colocadas em frascos submetidos à agitação até a mistura se tornar um coloide. A barra de agitação magnética foi então imersa nesta solução coloide e este sistema foi colocado em banho de água purificada. Depois do processo de gelificação, a barra foi lavada com uma solução de ácido acético/metanol para remoção do solvente e da MM. O filme de MIP 
apresentou alta afinidade por $L$-glutamina além de ter atingido o equilíbrio de adsorção mais rapidamente quando comparado ao polímero impresso pela forma convencional, in bulk. A barra de agitação impressa apresentou ainda maior seletividade pela $L$-glutamina do que por seus isômeros, diferença esta que não foi observada com o material não impresso ${ }^{[81]}$.

Também visando as enantiosseparações, Barrio et al. reportaram o desenvolvimento de um MIP com afinidade pelo $S$-citalopram utilizando modelagem computacional para a seleção dos MF e da relação MM-MF. O polímero foi sintetizado por polimerização radicalar inicializada por ultravioleta sobre uma barra de agitação magnética com o objetivo de se obter um sistema de SBSE capaz de realizar o reconhecimento enantiomérico seletivo. A barra de agitação foi inserida no interior de um tubo de Teflon com uma das extremidades fechadas, na qual foi colocada, com o auxílio de uma seringa, a mistura de polimerização. Outro tubo de Teflon foi utilizado para fechar a outra extremidade do sistema, que foi então exposto à radiação ultravioleta. Em seguida, a barra foi retirada do tubo e lavada com metanol. O material desenvolvido se mostrou capaz de extrair seletivamente o $S$-citalopram da mistura racêmica em um meio aquoso com alta especificidade. O procedimento otimizado é simples, rápido e permite a detecção e quantificação da droga em concentrações da ordem de $\mu \mathrm{g} \mathrm{L}^{-1}$ sem a necessidade da separação cromatográfica quiral ${ }^{[82]}$.

Com o objetivo de analisar nicosulfuron em amostras de água e solo, Yang, Zhao e Zhou descreveram o preparo de uma barra de agitação recoberta por um polímero monolítico impresso molecularmente utilizando o analito como MM. O material molecularmente impresso foi preparado através de polimerização in situ. A mistura de reação foi colocada no interior de um tubo de politetrafluoretileno, na qual já estava posicionada uma barra de agitação magnética. Ao final do processo de polimerização, a barra passou por etapas de lavagem com ácido acético - acetonitrila, acetonitrila apenas e água duplamente destilada. A técnica de extração em barra sortiva foi acoplada a HPLC-UV e o método apresentou bons resultados de recuperação e reprodutibilidade. Este material pôde ser reutilizado por mais de cem vezes sem perder sua eficiência ${ }^{[83]}$.

Para análise de alimentos, Wang et al. reportaram a utilização de um método para determinação de ractopamina em carne de porco utilizando eletroquimioluminescência combinada à MISBSE. Uma barra molecularmente impressa com ractopamina foi utilizada no pré-tratamento da amostra, com o objetivo de eliminar compostos coexistentes. A solução de polimerização foi colocada em uma seringa de polipropileno mantida a $60{ }^{\circ} \mathrm{C}$ por uma hora; em seguida, a barra de agitação foi imersa verticalmente no centro da mistura. O tubo foi selado e mantido a $60{ }^{\circ} \mathrm{C}$ por 20 horas. Depois da polimerização, o material foi retirado da seringa, lavado com solução de ácido acético - água e água duplamente deionizada repetidas vezes e sonicado à temperatura ambiente para remoção de substâncias remanescentes da síntese. Os resultados mostraram que o material pôde ser utilizado por pelo menos dez vezes sem perder sua capacidade de extração ${ }^{[84]}$.

Li et al. vêm desenvolvendo diversos trabalhos utilizando MISBSE em diferentes áreas de aplicação. Em geral, as barras impressas são preparadas através de ligações químicas do MIP a uma barra de vidro através da sililação da superfície do substrato e reação de copolimerização. Em 2010, o grupo desenvolveu um método para determinação de compostos $\beta 2$-agonistas em amostras de carne de porco, fígado e alimentos através da MISBSE e análise por HPLC. Sob as condições de extração otimizadas, a barra reves- 
tida por MIP mostrou maior capacidade de extração que a barra revestida por NIP para os analitos ractopamina, isoxsuprina, clembuterol e fenoterol. Além disso, as barras revestidas por MIP puderam ser usadas por pelo menos quarenta vezes sem perda de eficiência na extração. O método desenvolvido apresentou bons resultados em relação aos parâmetros de validação ${ }^{[85]}$.

Ainda em 2010, os autores descreveram o uso de MISBSE para extração seletiva de herbicidas triazínicos. A barra revestida com MIP apresentou maior seletividade e boa capacidade de pré-concentração para os compostos triazínicos estruturalmente relacionados, em comparação com a barra revestida de NIP. O material foi usado com sucesso para extração seletiva de triazinas de diversas amostras (arroz, maçã, alface e solo) com bons valores de recuperação ${ }^{[86]}$.

A técnica também ganhou destaque em 2011, quando o mesmo grupo de pesquisa relatou o uso de MISBSE para extração seletiva de sulfonamidas. A capacidade de adsorção do revestimento de MIP foi 4,6 vezes maior que a do NIP, e o material revestido com o MIP pôde extrair sulfametazina seletivamente para análise por HPLC-UV mesmo em baixas concentrações $\left(0,2 \mu \mathrm{g} \mathrm{L} \mathrm{L}^{-1}\right)$. O material apresentou excelente seletividade para moléculas análogas à MM. Houve ainda o desenvolvimento de um método utilizando a MISBSE combinada com a técnica de HPLC-UV para análise simultânea de oito sulfonamidas em amostras de carne de porco, fígado e frango ${ }^{[87]}$.

Com a finalidade de extrair e analisar fungicidas triazólicos em amostras de solo, em 2011, os autores desenvolveram um método simples e rápido utilizando MISBSE. Eles sintetizaram uma barra de agitação revestida por MIP, utilizando triadimefom como MM. O material mostrou habilidades de reconhecimento molecular não apenas para o triadimefom, mas também para compostos estruturalmente relacionados como triadimenol, diniconazol, flutriafol, hexaconazol, tebuconazol, paclobutrazol e uniconazol. O método apresentou limites de detecção na faixa de 0,14 a $0,34 \mu \mathrm{g} \mathrm{L}^{-1}$ e recuperações de $86,7 \%$ a $114,6 \%$ para amostras de solo fortificadas ${ }^{[88]}$.

\subsection{Microextração em fase sólida molecularmente impressa - MISPME}

A microextração em fase sólida (SPME) surgiu com o intuito de eliminar alguns problemas relacionados ao preparo de amostras pela SPE convencional, principalmente com relação ao elevado consumo de solventes orgânicos e à necessidade de utilização de grandes quantidades de amostras ${ }^{[89]}$. O dispositivo básico de SPME consiste de um bastão de sílica fundida de aproximadamente $100 \mathrm{~nm}$ de diâmetro, recoberto com um filme fino de um polímero ou de um sólido adsorvente. A extração ocorre mergulhando-se a seção recoberta na amostra ou no seu headspace. Por afinidade, analitos orgânicos migram da matriz para a fibra, onde são concentrados de acordo com seus coeficientes de partição. Depois disso, os analitos são termicamente dessorvidos diretamente no injetor de um cromatógrafo a gás ou eluídos com solventes para posterior análise por outras técnicas cromatográficas ${ }^{[90,91]}$.

Com o objetivo de melhorar a seletividade da fibra de SPME, os polímeros de impressão molecular vêm sendo empregados em conjunto com essa técnica. Isto ocorre quando os MIPs revestem a fibra comercial ou a substituem ${ }^{[92]}$. Como consequência, muitos autores relatam o uso desta técnica para o preparo de amostras.

De acordo com Prasad et al., a utilização de um MIP para o recobrimento de uma fibra de carbono foi eficiente na determinação de ácido fólico em matrizes complexas. O recobrimento foi utilizado para melhorar a baixa porosidade, baixa estabilidade e fragilidade associadas às 
fibras de MISPME. O MIP foi preparado utilizando um monômero novo, 2,4,6-trisacrilamido-1,3,5-triazina (TAT) e o ALC EGDMA (razão 1:20) em dimetilsulfóxido (DMSO) através do método de polimerização radicalar. A fibra de carbono, quando usada sem recobrimento, não foi eficiente para extrair ácido fólico das amostras; porém, quando a fibra de carbono recoberta pelo MIP foi utilizada para a extração, excelentes resultados foram obtidos ${ }^{[93]}$.

$\mathrm{O}$ uso de anabolizantes tem sido muito difundido para finalidades estéticas, principalmente para rápida hipertrofia muscular. Assim, Qiu et al. desenvolveram uma fibra para MISPME para a determinação de anabólicos esteroides. O MIP foi preparado pela copolimerização de MAA e TRIM, utilizando a testosterona como MM. Para a síntese do MIP, a MM foi dissolvida em acetonitrila e em MAA, e, após 12 horas, foram adicionados o TRIM e o AIBN. A fibra que receberia o revestimento de MIP passou por procedimentos de retirada de poliamida da superfície. Depois desses processos, ela foi introduzida na solução pré-polímero e colocada em um forno a $60^{\circ}$ para executar a polimerização. Essa fibra mostrou-se altamente seletiva, quimicamente estável e robusta, podendo ser conectada diretamente ao GC-MS. Foram otimizados o tempo de polimerização, o solvente de polimerização e o ALC. A caracterização do material foi feita por microscopia eletrônica de varredura (MEV), FT-IR e análise termogravimétrica. A fibra mostrou alta seletividade e habilidade de extração para quatro anabólicos esteroides em urina humana, com limite de detecção de 0,008-0,020 ng mL ${ }^{-1[92]}$.

Para monitorização terapêutica de $\beta$-bloqueadores, $\mathrm{Hu}$ et al. sintetizaram um polímero para revestimento de fibras de SPME pelo método de copolimerização múltipla, utilizando como MM o propranolol. A fibra resultante mostrou-se homogênea, altamente reticulada e porosa. O método foi aplicado para controle simultâneo de pindolol e propranolol em amostras de urina e de plasma humano com baixos limites de detecção e quantificação ${ }^{[94]}$.

A pesquisa de contaminantes em alimentos é de extrema importância para atestar a sua qualidade para o consumo. Assim, a síntese de uma fibra molecularmente impressa foi proposta para extração seletiva de atrazina em cebola, água e arroz, por Djozan e Ebrahimi. A fibra foi obtida utilizando atrazina como MM, MAA, EGDMA e AIBN. Para sintetizar o pré-polímero, a MM foi dissolvida em acetonitrila e, posteriormente, foram adicionados o MAA, EGDMA e o AIBN. A mistura foi desgaseificada. Então, o pré-polímero foi introduzido em um capilar e colocado em banho de água a $65^{\circ} \mathrm{C}$ para ocorrer a copolimerização. A fibra foi retirada do capilar e introduzida em um homemade de SPME. Foi verificado que o material apresentava alta seletividade, baixo custo, estabilidade térmica e química. Fatores como pH e temperatura de extração foram otimizados. Como resultado, o método demonstrou eficiência na extração de atrazina, simazina, propazina, cianazina, ametrina, terbutrina e prometrina ${ }^{[95]}$.

Também neste sentido, $\mathrm{Hu}$ et al. produziram um MIP para revestir a fibra de SPME, pelo método de copolimerização múltipla, seletiva a hormônios esteroides. Esta apresentou alta porosidade, estabilidade química e térmica e pôde ser acoplada diretamente aos instrumentos de cromatografia. A fibra molecularmente impressa exibiu uma maior afinidade para o $17 \beta$-estradiol (MM) em comparação às fibras comerciais e ao NIP. A fibra também foi seletiva aos compostos análogos ao $17 \beta$-estradiol como estriol, estrona e 17a-etinilestradiol. O método demons- 
trou alta eficiência na extração de estrógenos em amostras de peixes, com limite de detecção $0,98-2,39 \mu \mathrm{g} \mathrm{L}-1[96]$.

$\mathrm{O}$ uso de herbicidas é muito difundido em culturas agrícolas. Estes podem apresentar toxicidade para os consumidores quando presentes em concentrações maiores que os limites máximos permitidos. Neste sentido, $\mathrm{Hu}$ et al. sintetizaram uma fibra de SPME utilizando metolachlor como MM. Para circundar o problema de fragilidade, o MIP sintetizado revestiu a superfície de uma fibra de aço inoxidável. Para a preparação do polímero, MM, MAA, AIBN e TRIM foram adicionados a uma solução de tolueno e misturados por 12 horas com o auxílio de um oscilador. O pré-polímero foi introduzido em um tubo para a retirada de oxigênio e, posteriormente, introduziu-se a fibra de aço inoxidável para realizar a polimerização. Foram sintetizadas nove fibras de diferentes composições, variando-se os MFs, as MM e os ALCs. A fibra que apresentou melhor desempenho na extração seletiva de metolachlor em soja e milho foi aquela sintetizada a partir de tolueno, MAA e TRIM. O material apresentou rápida adsorção e dessorção, sendo seletivo para a extração de metolachlor e outros herbicidas e seus produtos de degradação. Os limites de detecção para metolachlor, propisochlor e butaclor em amostras de milho e soja, foram de 3,0; 9,6 e $38 \mu \mathrm{g} \mathrm{L} \mathrm{L}^{-1}$, respectivamente. Foi verificado que a proporção de monômero em relação ao ALC foi de extrema importância para a seletividade do $\mathrm{MIP}^{[97]}$.

Em um trabalho realizado por Barahona et al., foi desenvolvido um método empregando-se MISPME para análise de tiabendazol em amostras de suco de laranja. Para a síntese da fibra, TBZ (tiabendazol), MAA, TRIM e AIMN (2,2'-azobis-2-metilbutironitrilo) foram misturados com uma solução de tolueno: $\mathrm{MeOH}$ $(1: 1 \mathrm{v} / \mathrm{v})$. Posteriormente, a solução do pré-polí- mero, com a ajuda de uma seringa, preencheu o interior de capilares. Estes foram colocados em um forno a $65{ }^{\circ} \mathrm{C}$ para ocorrer a polimerização. Depois de algumas horas, o MIP foi lavado com uma solução de $\mathrm{MeOH}$ ácido acético $(1: 1, \mathrm{v} / \mathrm{v})$ para a remoção da molécula modelo. Visando resolver alguns problemas relacionados ao reconhecimento molecular dos analitos em meio aquoso, a fibra molecularmente impressa foi inserida dentro de um capilar de polipropileno para que uma extração prévia por LPME fosse realizada antes da SPME. A metodologia foi validada e aplicada com êxito. O método mostrou-se linear, exato, robusto e preciso, comprovando que a combinação entre MISPME e LPME foi eficiente ${ }^{[98]}$.

Nesta mesma linha de pesquisa, Hu et al. ${ }^{[99]}$ propuseram um método baseado em LPME e MISPME para análise de triazinas em amostras complexas (urina, lama, leite e melancia). Neste estudo, o MIP foi utilizado para revestir a fibra de sílica empregada na SPME. Antes do revestimento, essa fibra passou por um processo de sililação, que ocorreu por imersão em uma solução 10\% (v/v) 3-(metacriloxi) propiltrimethoxisilano em acetona à temperatura ambiente. Para a síntese do MIP, foi utilizado terbutilazina como MM. A MM juntamente com o MAA foram dissolvidos em tolueno e incubados por 12 horas. Posteriormente, foram introduzidos o TRIM e AIBN. A solução do pré-polímero foi transferida para um tubo, no qual passou por um processo de retirada de oxigênio e polimerização. Os analitos foram extraídos primeiramente por LPME e posteriormente pela fibra SPME. Foi verificado que a união das duas técnicas melhorou a extração dos analitos alvos em comparação com a técnica de MI-SPME isoladamente. O método proposto aumentou o desempenho analítico e diminuiu o tempo de pré-tratamento da amostra. 
O uso de ftalatos em indústrias é muito comum. Estes são utilizados como aditivos para deixar o plástico mais maleável. Contudo, tal classe de compostos é tida como cancerígena, podendo causar danos ao fígado, rins e pulmão, além de anormalidade no sistema reprodutivo. Dessa forma, é de extrema importância monitorar os níveis de ftalatos oriundos de resíduos industriais no meio ambiente. Neste sentido, He et al. sintetizaram uma fibra molecularmente impressa, para SPME, pelo método de polimerização in bulk, utilizando dibutil ftalato (DBP) como molécula modelo. A MM, juntamente com MAA, foi dissolvida em clorofórmio e, em seguida, foram adicionados o AIBN e EGDMA. A solução passou pelo processo de retirada de oxigênio. Depois do processo de desgaseificação, a solução foi introduzida em um capilar de vidro, no qual ocorreu o processo de polimerização a $60{ }^{\circ} \mathrm{C}$. A fibra sintetizada mostrou seletividade aos ftalatos e foi empregada para análise de amostras de águas ambientais. Quando comparada à fibra não impressa, a fibra impressa foi mais seletiva ao dibutilftalato (DBP) e aos seus análogos dimetilftalato (DMP), dietilftalato (DEP), diamilftalato (DAP) e dioctilftalato (DNOP). Excelentes recuperações foram observas e atribuídas ao mecanismo de adsorção seletiva da fibra molecularmente impressa. Os limites de detecção alcançados estavam compreendidos entre 2,17 e 20,84 ng L ${ }^{-1}$ e a recuperação, entre $94,54 \%$ e $105,34 \%{ }^{[53]}$.

Também para análise de amostras ambientais, um novo método empregando MISPME e HPLC-UV foi desenvolvido por Feng et al. A fibra molecularmente impressa foi sintetizada utilizando-se 2,4,6-triclorofenol como MM, MAA e DVB. Esta demonstrou boa capacidade de pré-concentração e seletividade para análise de compostos fenólicos em amostras de água. As recuperações foram de 88,9\%-102,5\% para amostras de água de torneira, 80,0\%-94,0\% para água de rio e $80,0 \%-90,5 \%$ para água de esgoto ${ }^{[100]}$.

\subsection{Polímeros magnéticos molecularmente impressos - MIPs Magnéticos}

Os polímeros molecularmente impressos têm a capacidade de reconhecimento seletivo através dos sítios formados e da força de ligações remanescentes no momento em que a MM é reti$\operatorname{rada}^{[101]}$. Quando reagentes com características magnéticas (por exemplo o $\mathrm{Fe}_{3} \mathrm{O}_{4}$ ) são empregados na síntese desses polímeros, o isolamento das partículas de MIP da matriz pode ocorrer simplesmente com a aplicação de um campo magnético. A rede polimérica evita a dispersão das partículas magnéticas e melhora as propriedades mecânicas dessas partículas ${ }^{[102]}$.

Em um trabalho realizado por Wang et al., foi proposta uma síntese de um polímero magnético molecularmente impresso por polimerização em suspensão com aquecimento em micro-ondas. Foi utilizado 2-amino-4 nitrofenol (4-NAP) como $\mathrm{MM} \mathrm{e} \mathrm{Fe}_{3} \mathrm{O}_{4}$ como partícula magnética. Como suporte para síntese, foi utilizado volastonite, o que resultou em um menor tempo de polimerização e uma melhor morfologia do polímero. Bons resultados foram obtidos, não somente com relação à boa seletividade e afinidade para 4-NAP em amostras aquosas, mas também com relação ao superparamagnetismo quando o material foi exposto a um campo magnético externo ${ }^{[102]}$.

O sesamol é um composto orgânico utilizado na síntese de alguns medicamentos. Neste sentido, Wang et al. sintetizaram um polímero magnético molecularmente impresso, empregando piperonal como MM. Para preparar o volastonite magnético, volastonite carboxilado foi dissolvido em 1-metil-2-pirrolidona sob 
ação de ultrassom e, posteriormente, foi adicionado acetilacetonato de ferro (III) (partícula magnética). O polímero foi utilizado para reconhecimento de sesamol (análogo ao piperonal) em amostras aquosas. Este demonstrou boa estabilidade térmica e propriedades magnéticas satisfatórias. A isoterma de adsorção mostrou melhor ajuste ao modelo de Langmuir quando comparado ao modelo de Freundlich. Por fim, o método demonstrou capacidade de reconhecer seletivamente o sesamol ${ }^{[103]}$.

Um MIP magnético com reconhecimento seletivo para 2,4-diclorofenol foi proposto por Pan et al. Para evitar a dispersão das partículas de $\mathrm{Fe}_{3} \mathrm{O}_{4}$ e a fragilidade do polímero, o material foi obtido através da coprecipitação de atapulgita/ $\mathrm{Fe}_{3} \mathrm{O}_{4}$ a partir de uma suspensão de atapulgita pré-modificada com $\mathrm{FeCl}_{3}$. O MIP foi sintetizado utilizando 2,4-diclorofenol como MM, MAA, AIBN e EGDMA. Em seguida, as partículas magnéticas foram revestidas com uma fina película do MIP. O polímero exibiu estabilidade térmica e propriedade magnética adequada para separação. A isoterma de adsorção foi mais bem ajustada ao modelo de Langmuir, e a capacidade máxima de adsorção do material foi de 145,79 $\mathrm{mg} \mathrm{g}^{-1}$. Depois de cinco extrações, o polímero ainda exibiu boa seletividade, o que deixou claro para os pesquisadores que os polímeros magnéticos são candidatos promissores para separação de poluentes ${ }^{[104]}$.

Ainda para análises de compostos fenólicos, Pan et al. desenvolveram um material que agregava nanopartículas magnéticas a um nanotubo haloísta. As partículas magnéticas foram ligadas aos ácidos carboxílicos dos nanotubos de haloisita (HNTs-COOH) por meio de uma reação de triacetilacetonato férrico em 1-metil-2-pirrolidona a alta temperatura. As partículas magnéticas de nanotubo haloísta (MHNTs) foram revestidas com o polímero molecularmente impresso para reconhecimento específico de 2,4,6-triclorofenol. O polímero exibiu boas propriedades magnéticas e alta estabilidade térmica. A isoterma de adsorção foi ajustada ao modelo de Langmuir. A capacidade de adsorção máxima foi de $246,73 \mathrm{mg} \mathrm{g}^{-1}$ a $298 \mathrm{~K}$. Os experimentos demonstraram que o material apresentou alta seletividade e afinidade para compostos fenólicos em amostras ambientais. Os MIPs preparados foram facilmente separados da suspensão por um campo magnético externo. Foi concluído que ligações de hidrogênio entre os compostos fenólicos e o MAA (MF) foram as principais responsáveis pelo mecanismo de reconhecimento $^{[105]}$.

Wang et al. obtiveram um polímero a partir de polimerização radicalar utilizando metacriloxipropiltrimetoxisilano (MEMO) e, posteriormente, uma copolimerização, utilizando MAA, EGDMA e $17 \beta$-estradiol como MM. Nanopartículas magnéticas de $\mathrm{Fe}_{3} \mathrm{O}_{4}$ foram empregadas para conferir propriedades magnéticas ao polímero que, ao final do processo, apresentou elevada seletividade, grande capacidade de adsorção e rápida capacidade de ligação para os analitos de interesse. O método foi linear, com coeficiente de correlação de 0,9996. A capacidade máxima adsortiva do MIP magnético foi de $225,68 \mu \mathrm{mol} \mathrm{g}{ }^{-1}$ e do NIP magnético

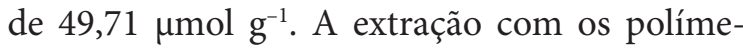
ros magnéticos molecularmente impressos em conjunto com a técnica de HPLC-UV foi útil na determinação de estrogênios em amostras de ração ${ }^{[106]}$.

Em um estudo recente realizado por Ding et al., um MIP magnético foi sintetizado para extração seletiva de sildenafil e verdanafil em suplementos alimentares à base de plantas. Depois da extração, as amostras foram analisadas por HPLC-UV. O polímero foi impresso utilizando sildenafil como MM, ácido acrílico 
2-trifluorometil como MF, EGDMA como ALC e $\mathrm{Fe}_{3} \mathrm{O}_{4}$ como partícula magnética. Os dados foram ajustados conforme o modelo da isoterma de Freundlich ${ }^{[107]}$.

Para o enriquecimento seletivo de $\beta$-antagonistas em amostras de fígado e carne de porco, foi sintetizado um polímero magnético molecularmente impresso por polimerização em suspensão com aquecimento por micro-ondas. As partículas magnéticas foram sintetizados por coprecipitação em um meio contendo $\mathrm{FeCl}_{3}$ e $\mathrm{FeSO}_{4}$ em solução aquosa de amoníaco (28\% em peso). $\mathrm{O}$ aquecimento por micro-ondas foi empregado como alternativa para acelerar o processo de polimerização. A isoterma foi ajustada ao modelo de Freundlich, e a capacidade máxima adsortiva para o MIP magnético foi de 3,24 $\mathrm{g} \mathrm{mol}^{-1}$ e para o NIP magnético foi de $1,17 \mu \mathrm{g} \mathrm{mol}^{-1}$, demonstrando uma maior capacidade de adsorção para o polímero impresso. O material foi utilizado com sucesso para extração de ractopamina, isoxsuprina e fenoterol em carne e fígado de porco, seguido de análise por HPLC-UV. O método proposto apresentou uma boa linearidade e baixos limites de detecção e quantificação $^{[108]}$.

A determinação seletiva de antibióticos $\beta$-lactâmicos em amostras de leite por MIP magnético foi proposta em estudo feito por Zhang et al. Para a síntese do polímero, eles utilizaram penicilina $\mathrm{V}$ potássica ( $\mathrm{PENV}$ ) como MM, MAA, EGDMA e $\mathrm{Fe}_{3} \mathrm{O}_{4}$ como partícula magnética. $\mathrm{O}$ polímero sintetizado apresentou alta seletividade e afinidade para PENV e outros compostos análogos aos $\beta$-lactâmicos. O processo de extração foi realizado em uma única etapa em que foram misturados os solventes de extração, amostra de leite e o MIP magnético sob agitação em ultrassom. Depois de se completar o processo de extração, os analitos adsorvidos pelo MIP magnético foram separados da matriz por um ímã externo. Posteriormente os analitos foram analisados por LC-MS. A partir das análises, foi possível observar bons níveis de recuperação e baixos limites de detecção e quantificação para $\beta$-lactâmicos. Em comparação com métodos convencionais, a utilização do MIP magnético permitiu, de maneira rápida e fácil, a separação e identificação dos analitos de interesse ${ }^{[109]}$.

Gai et al. sintetizaram um polímero magnético molecularmente impresso utilizando albumina de soro bovino (BSA) como MM. As partículas magnéticas $\mathrm{Fe}_{3} \mathrm{O}_{4} / \mathrm{NH}_{2}$ foram adicionadas a uma mistura de tetra-hidrofurano $(30 \mathrm{~mL})$ e trietilamina ( $1 \mathrm{~mL})$. O MIP foi sintetizado baseado em polimerização radicalar na presença de $\mathrm{N}$-isopropilacrilamida e N-[3 -(dimetilamino) propil]-metacrilamida (MFs) para a extração de proteínas. O polímero impresso apresentou uma maior capacidade de adsorção e seletividade a BSA em comparação ao polímero não impresso $^{[110]}$.

Também para análise de proteínas, um método baseado em extração com MIP magnético e análise por quimioluminescência foi desenvolvido por Jing et al. para extração seletiva de lisozima em urina humana de pacientes com problemas renais. As nanopartículas de $\mathrm{Fe}_{3} \mathrm{O}_{4}$ foram sintetizadas pelo método de coprecipitação e, em seguida, revestidas com uma fina camada de MIP. O MIP foi sintetizado usando a lisozima como MM, MAA, acrilamida e N,Nmetilenebisacrilamida. $\mathrm{O}$ método mostrou-se rápido, de baixo custo e altamente seletivo, quando comparado aos métodos tradicionais. A extração foi completada em apenas 12 minutos, com recuperações de 90,1\%-103,7\% e limite de quantificação de $5 \mathrm{ng} \mathrm{mL} \mathrm{m}^{-1}$. O método demonstrou ser confiável e muito prático, deixando claro para os pesquisadores que este poderá ser muito promissor para análises de rotina a fim de se diagnosticar doenças renais ${ }^{[111]}$. 
Para análise simultânea de três esteróis (ergosterol, stigmasterol e $\beta$-sitosterol) em amostras complexas, um MIP magnético, utilizando $\beta$-sistrol como MM, foi sintetizado por Zhan et al. ${ }^{[112]}$.

A síntese das nanopartículas magnéticas foi realizada empregando-se $\mathrm{Fe}_{3} \mathrm{O}_{4}$ como partícula magnética. A MM e o MF foram dissolvidos em tolueno. Na solução do pré-polímero, foram adicionadas as partículas magnéticas, estireno, EGDMA e AIBN, sob agitação. A polimerização ocorreu sob irradiação por micro-ondas. As extrações foram realizadas em amostras de cogumelos, soro e melancia. O polímero impresso demonstrou uma recuperação 20 vezes superior ao polímero não impresso. As condições ótimas de extrações foram estudadas. As recuperações encontradas para amostras de cogumelos foram de $80,9 \%-86,0 \%$ para ergosterol, 75,8\%-77,2\% de estigmasterol e 74,2\%-80,8\% para $\beta$-sitosterol. Para as amostras de soro foram encontrados os seguintes valores: $86,2 \%-88,2 \%$ de estigmasterol e $72,4 \%-79,4 \%$ para $\beta$-sitosterol. Para as amostras de melancia, as recuperações encontradas foram: $71,6 \%-74,9 \%$ para ergosterol, $81,0 \%-84,5 \%$ para estigmasterol e 71,6\%-76,9\% para sitosterol. Diante desses resultados, os pesquisadores concluíram que o método proposto é aplicável e confiável para análise simultânea de esteróis em amostras biológicas ${ }^{[12]}$.

Para o reconhecimento seletivo de lisozima, foi sintetizado através de copolimerização um polímero magnético em que a capacidade magnética foi transmitida através do encapsulamento de $\mathrm{Fe}_{3} \mathrm{O}_{4}$. Neste trabalho, Jing et al. tiveram como resultado a alta capacidade de adsorção $\left(0,11 \mathrm{mg} \mathrm{mg}^{-1}\right)$, seletividade controlada e separação magnética $\left(22,1 \mathrm{emug}^{-1}\right)$. Depois da pré-concentração e purificação dos analitos pelo
MIP, eles foram submetidos ao método de quimioluminescência para determinação seletiva de lisozima em amostras de soro humano ${ }^{[113]}$.

Em um estudo realizado por Wang et al., uma nanopartícula magnética de $\mathrm{Fe}_{3} \mathrm{O}_{4}$ foi revestida por polímeros molecularmente impressos, utilizando uma estratégia de impressão semicovalente para reconhecimento seletivo de estrona. A MM (estrona) revestia a sílica sobre o núcleo de óxido de ferro através de uma ligação termicamente reversível. A remoção da molécula modelo por uma simples reação térmica produziu sítios específicos na sílica para reconhecimento de estrona. A partir dos experimentos realizados, os pesquisadores acreditam que os MIPs magnéticos são candidatos promissores para separações químicas e bioquímicas ${ }^{[114]}$.

Ding et al., ${ }^{[115-117]}$ em seus trabalhos, propuseram a síntese de polímeros magnéticos para a determinação de resíduos de fármacos em diferentes amostras. Para a determinação de fluoroquinolonas em amostras de água, foi sintetizado um MIP magnético para realizar a extração dos analitos e posterior análise por LC-MS. O ciprofloxacino foi utilizado como MM, além de MAA, EGDMA e $\mathrm{Fe}_{3} \mathrm{O}_{4}$ como partícula magnética. Bons níveis de recuperação e baixos limites de detecção e quantificação foram alcançados. Em conclusão, o método proposto teve sucesso na determinação de fluoroquinolonas incluindo ciprofloxacino, enrofloxacino, lomefloxacino, levofloxacino, fleroxacino e sparfloxacino em diferentes amostras de águas ambientais ${ }^{[115]}$. Para determinação de sulfonamida (SAs) em mel, um MIP magnético foi sintetizado a partir de MAA, EGDMA, SMD, dimetil sulfóxido e $\mathrm{Fe}_{3} \mathrm{O}_{4}$. A extração foi feita sob agitação e após se completar, o polímero foi capturado e separado da matriz por atração magnética externa. Os extratos foram analisados por LC-MS e o método proposto permitiu a extração de sulfonamidas e seus 
análogos em diferentes amostras de mel ${ }^{[116]}$. Para a análise de tetraciclinas em amostras de tecido e ovo, um MIP magnético foi sintetizado usando oxitetraciclina como MM, MAA, estireno e divinilbenzeno como componente da matriz polimérica e $\mathrm{Fe}_{3} \mathrm{O}_{4}$ como componente magnético. $\mathrm{O}$ processo de extração e limpeza ocorreu em um único passo. Depois da extração se completar, o polímero foi separado da matriz por uma atração magnética externa com posterior análise por LC-MS. Em comparação com os métodos tradicionais de preparo de amostras (LLE e SPE, por exemplo), esse método apresentou a vantagem da utilização mínima de amostras e baixo consumo de solventes, tornando-o muito promissor para determinação de resíduos de fármacos ${ }^{[117]}$.

\subsection{Microextração por sorvente empacotado molecularmente impressa - MEPS-MIP}

A microextração por sorvente empacotado (MEPS) é uma nova técnica miniaturizada de extração em fase sólida. Ela difere das técnicas convencionais de SPE devido ao menor tempo de extração e o menor consumo de reagentes orgânicos. Este dispositivo também pode ser utilizado por várias vezes, sem que haja substituição. Esta técnica consiste de uma seringa (100-250 $\mu \mathrm{L})$ contendo uma pequena coluna que resguarda o sorvente ${ }^{[118]}$. A amostra é aspirada e dispensada várias vezes para que haja a extração e, em seguida, um solvente de eluição é aspirado e dispensado diretamente no cromatógrafo. A união de MEPS com o MIP têm sido bastante promissora e útil para determinação de vários analitos em amostras complexas.

Para determinação de fluoroquinolona em amostras de água, foi sintetizado um MIP utilizando ciprofloxacino como MM. Neste trabalho, Prieto et al. empacotaram o polímero em um dispositivo de MEPS e este foi utilizado como sorvente para extração com posterior análise por LC-MS. Para comparar a eficiência do MIPMEPS, os analitos alvos também foram determinados por MISPE. Os pesquisadores obtiveram elevada seletividade para os analitos de interesse por ambas as técnicas. $\mathrm{O}$ método proposto permitiu a análise de compostos em níveis de concentração baixíssimos (ng L $\left.{ }^{-1}\right)$ com baixo consumo de solventes orgânicos e menor tempo de análise ${ }^{[118]}$. Já para análise de compostos que causam distúrbios endócrinos, os mesmos pesquisadores sintetizaram um polímero seletivo a alquilfenóis, bisfenol A (BPA), hormônios naturais e sintéticos em amostras de águas residuais. O $17 \beta$-estradiol foi utilizado como MM, etileno glicol dimetacrilato como monômero de reticulação, acetonitrila como solvente e uma combinação de ácido metacrílico e ácido p-vinilbenzoico como monômeros funcionais. $\mathrm{O}$ material foi comparado a dispositivos comerciais que utilizam C18 como adsorvente, em termos de eficiência de extração, e mostrou-se mais eficiente para análise de contaminantes emergentes ${ }^{[19]}$.

\subsection{Extração por dispersão em fase sólida molecularmente impressa - MSPD-MIP}

A extração por dispersão da fase sólida (MSPD- do inglês matrix solid-phase dispersion) tem sido aplicada principalmente para o preparo de amostras sólidas, semissólidas ou muito vis$\operatorname{cosas}^{[120]}$. Devido à complexidade dessas amostras, geralmente é necessário que se realizem várias etapas de extração, tornando o procedimento moroso e muito suscetível a erros. A MSPD tem como objeto principal minimizar o número de etapas do processo de preparo, mantendo a mesma eficiência de remoção de impurezas. Normalmente, a amostra é triturada empregando-se um solvente orgânico e, em seguida, centrifugada. O sobrenadante é colocado dire- 
tamente em contato com um adsorvente (normalmente sílica) que captura os interferentes deixando os analitos livres no sobrenadante. No entanto, outra etapa de purificação normalmente é requerida devido à ineficiência dos adsorventes. No intuito de minimizar o número de etapas de extração, bem como melhorar a seletividade do processo, os MIPs têm sido utilizados como adsorventes em MSPD. Contudo, cabe ressaltar que, nessa aplicação de MSPD, o adsorvente (no caso o MIP) é utilizado para capturar os analitos e não os interferentes como descrito no MSPD convencional. A amostra é triturada juntamente com o MIP para que ocorra a adsorção dos analitos. Em seguida, o polímero é lavado para retirada dos interferentes e os analitos são dessorvidos e analisados ${ }^{[121-123]}$.

Yan et al. ${ }^{[124]}$ foram os primeiros a propor o uso do MIP na extração por dispersão da fase sólida e empregaram esta técnica no preparo de amostras para análise de fluoroquinolonas em ovo, ${ }^{[124]}$ carne $^{[120,124]}$ e em soro ${ }^{[123,125]}$ por HPLC. As amostras foram preparadas pela homogeneização de quantidades iguais de amostra e do polímero, utilizando gral e pistilo. Posteriormente, a mistura foi transferida para um cartucho contendo o MIP sintetizado e eluído com uma solução adequada para remover o analito. Para análise em HPLC, o solvente empregado na extração da amostra foi evaporado e o resíduo foi ressuspenso com a fase móvel. A seletividade do MIP foi avaliada pelo tratamento das amostras por MSPD empregando adsorventes não seletivos como sílica, C18 e Florisil. Os MIPs apresentaram melhores resultados em termos de recuperação e seletividade se comparados aos demais adsorventes.

Yan et al. empregaram a MSPD em associação com a técnica de microextração líquido-líquido para determinação de corantes Sudan em gema de ovo. A DLLME é uma técnica rápida, simples e com alto potencial de enriquecimento. No entanto, não pode ser empregada para extração direta de amostras sólidas ou semissólidas. Assim, a amostra foi primeiramente extraída com MIP por agitação em gral e pistilo. Posteriormente, a mistura foi transferida para um cartucho contendo $50 \mathrm{mg}$ de MIP e eluída com uma solução de acetona/ácido acético (95:5-v/v). A amostra foi evaporada até um volume de $1 \mathrm{~mL}$. Depois da adição de $5 \mathrm{~mL}$ de tetracloroetileno, a solução foi agitada e centrifugada, e a fase inferior foi coletada com o auxílio de uma seringa. A análise foi feita por HPLC e os resultados demostraram que a associação de MSPD e LLME foi satisfatória na quantificação de Sudan em alimentos ${ }^{[26]}$. Esta técnica foi também empregada na análise de cloranfenicol em amostras de solo ${ }^{[127]}$ e carne de peixe ${ }^{[121]}$. Os polímeros foram sintetizados utilizando MAA e 4-VP como MF e EGDMA como ALC. As amostras foram extraídas por agitação direta com o MIP, como descrito anteriormente, e analisadas por HPLC.

O MIP tem sido aplicado com sucesso na MSPD no tratamento de amostras sólidas e viscosas, a fim de obter uma melhor recuperação dos analitos. Ademais, a utilização desta técnica de extração permite uma análise mais sensível, precisa e seletiva, além de minimizar consideravelmente o tempo do processo de preparo da amostra e o consumo de solvente.

\subsection{Extração por polímeros de impressão molecular restritos à ligação com macromoléculas - RAM-MIP}

Devido a sua alta seletividade, os MIPs são amplamente utilizados para extração e separação de diversos tipos de amostras. No entanto, alguns interferentes geralmente presentes nas amostras, como lipídeos e proteínas, podem diminuir dras- 
ticamente a seletividade destes polímeros ${ }^{[128]}$. Por outro lado, os materiais de acesso restrito (RAMs) apresentam uma excelente capacidade de eliminar a interferência de macromoléculas apesar de serem pouco seletivos ${ }^{[129]}$. Neste contexto, foi proposta a associação de ambas as tecnologias, a fim de se obter um polímero seletivo para purificação de amostras complexas e, ao mesmo tempo, incapaz de se ligar a macromoléculas. Esses materiais foram chamados de polímero de impressão molecular restrito à ligação com macromoléculas (RAM-MIP), os quais apresentam sítios específicos de reconhecimento molecular, bem como grupos hidrofílicos/protetores externos que bloqueiam a ligação com macromoléculas. Os RAM-MIPs são sintetizados pelos métodos tradicionais de síntese de MIP e posteriormente são revestidos para formação da camada hidrofílica, a qual impede o acesso de macromoléculas aos grupos ligantes do MIP.

Haginaka et al foram os precursores dessa tecnologia quando propuseram, em 1999, um MIP seletivo a (S)-naproxeno, empregando 4-VP e EGDMA como MF e ALC, respectivamente. Uma mistura de GMMA e GDMA na proporção de 1:1 (v/v) foi adicionada ao polímero quatro horas após o início da síntese para formação da camada hidrofílica. Para avaliar a seletividade, as amostras proteicas foram submetidas à extração com o RAM-MIP e como um MIP sintetizado pelo mesmo método, mas sem a adição dos monômeros hidrofílicos. A recuperação do analito foi a mesma em ambos os polímeros, demonstrando, portanto, que a seletividade não foi alterada pela camada hidrofílica. Além disso, após a percolação de uma solução de albumina bovina em ambos os polímeros, os autores obtiveram recuperações de $100 \%$ e $<10 \%$ para o RAM-MIP e MIP, respectivamente. O RAMMIP foi empregado com sucesso na análise direta de (S)-naproxeno em amostras de soro ${ }^{[130]}$.
Ainda nesta linha, o grupo sintetizou também um RAM-MIP empregando (S)-naproxeno ou ibuprofeno como molécula modelo, e os polímeros obtidos foram utilizados na análise direta de amostras de soro através do sistema column-switching ${ }^{[131]}$. A metodologia foi empregada na obtenção de RAM-MIPs para análise de anti-inflamatórios não esteroidais, ${ }^{[132]}$ antiepiléti$\cos ^{[133]}$ e bisfenol- $\mathrm{A}^{[134]} \mathrm{em}$ amostras de água de rio.

Outra metodologia para obtenção do RAM-MIP foi proposta por Puoci et al. Os autores obtiveram um polímero pelo método de polimerização in bulk utilizando cafeína como MM, MAA como MF, DVB como ALC e glicidilmetacrilato (GMA) como comonômero pro-hidrofílico. A camada hidrofílica foi criada pela abertura do anel epóxido da molécula de GMA, empregando uma solução de ácido perclórico. O principal objetivo dos autores foi obter um polímero para ser empregado em ambientes fisiológicos. Os estudos demonstraram que o RAM-MIP obtido utilizando o GMA como comonômero pro-hidrofílico pode ser empregado com sucesso neste tipo de ambiente ${ }^{[135]}$. Outros trabalhos do mesmo grupo relatam a síntese de RAM-MIPs para emprego em liberação controlada de p-aminofenol ${ }^{[136]}$. e para análise direta de sulfonamidas em leite ${ }^{[137]}$. Cabe destacar a eficácia de ambos os polímeros na eliminação de macromoléculas.

Um RAM-MIP foi preparado através do método de polimerização por inchaço, utilizando fenobarbital como molécula modelo, 4-VP como MF, EGDMA como ALC e um glicomonômero para obtenção da camada hidrofílica. O glicomonômero foi previamente preparado empregando-se octa-acetato de lactose, HEMA e trifluoreto de boro. Na segunda etapa do processo de polimerização, o glicomonômero foi adicionado e a síntese ocorreu por mais 1 hora 
à temperatura ambiente e por 24 horas a $50^{\circ} \mathrm{C}$ em atmosfera de argônio. Depois da síntese, uma solução de metóxido de sódio em metanol foi utilizada para promover a alcoólise do polímero para a formação da camada hidrofílica. O polímero sintetizado apresentou boa seletividade e capacidade de eliminar as macromoléculas e foi empregado na análise de fenobarbital em amostras de soro $^{[138]}$.

\subsection{Outros}

A extração em fase sólida em discos tem grandes aplicações principalmente na área ambiental por suportar grandes volumes de amostra. Porém, sua utilização associada a MIPs ainda parece ser pouco explorada. Alguns autores chegaram a descrever a síntese de membranas impressas, como Sergeyeva et al. Eles propuseram a modificação superficial de membranas com uma fina camada de um MIP seletivo para o herbicida triazínico terbumetona. Foi avaliada a capacidade das membranas de adsorverem a terbumetona, sendo que as membranas impressas mostraram maior capacidade de adsorção para a terbumetona do que para compostos similares (atrazina, desmetrina e metribuzina). A alta afinidade destas membranas sintéticas associada ao baixo custo do preparo delas mostraram que elas poderiam ser empregadas com sucesso em procedimentos de separação como SPE ${ }^{[139]}$.

Em outro estudo, Pap et al. descreveram um método de pré-tratamento de amostra em dois estágios para aplicação em amostras de águas de rios. Os autores propuseram a síntese de um MIP utilizando MAA como MF, EGDMA como ALC, terbutilazina como MM e tolueno como solvente porogênico. Num primeiro estágio, grandes volumes de água foram concentrados em um disco $\mathrm{C}_{18}$ e, em um segundo momento, a amostra passou por uma etapa de clean-up sele- tivo em $\mathrm{MIP}^{[140]}$. O acoplamento das duas técnicas poderia mais uma vez indicar uma tendência de MISPE em disco.

Suedee et al. estudaram a possibilidade de desenvolver um MIP para reconhecimento múltiplo utilizando uma mistura de tetraciclinas e seus produtos de degradação como molécula-modelo. Um agente plasticizante de polivinilcloreto e dibutilftalato foi empregado como matriz da membrana, e partículas de MIP foram incorporadas como fase de adsorção sólida para extração seletiva de tetraciclina e seus análogos (doxiciclina, clortetraciclina e oxiteraciclina) de soluções aquosas. A avaliação da extração foi realizada através de um método de diálise. Os resultados mostraram que a seletividade do polímero era específica para o grupo de compostos estruturalmente relacionados com o modelo, indicando a possibilidade de se utilizar o material preparado como fase de adsorção seletiva para remoção de tetraciclinas de ambientes aquáticos $^{[141]}$. O mesmo material poderia encontrar aplicações associado à extração em fase sólida sob a forma de discos.

Entre outros trabalhos de extração em fase sólida diferenciada, Tan et al. prepararam um MIP de prometrina sintetizado por polimerização térmica sobre a superfície de nanotubos de carbono de paredes múltiplas e desenvolveram uma técnica de microextração baseada no revestimento desse material por uma membrana porosa, integrando as vantagens da MISPME impressa com a LPME (microextração em fase líquida). Um sistema de microextração, composto de um clip de papel e uma membrana contendo nanotubos impressos, foi colocado sob agitação magnética e apenas os analitos alvo e as moléculas interferentes de tamanho menor que o poro da membrana foram extraídos na sua fase orgânica, ocorrendo a adsorção seletiva dos 
analitos no MIP, enquanto os interferentes permaneceram na fase orgânica e foram eluídos na etapa seguinte. O método, que combina filtração em membrana, LLE (extração líquido-líquido) e reconhecimento por impressão molecular, mostrou alta seletividade e capacidade de pré-concentração, além das vantagens de fácil operação e baixo consumo de solvente orgânico. A técnica se mostrou efetiva para a extração de herbicidas triazínicos de águas de rios, efluentes e amostras de leite ${ }^{[142]}$.

Em um estudo recente, uma fibra de sílica de $0,1 \mathrm{~cm}$ de diâmetro foi recoberta por um MIP sintetizado para análise de estrogênio em amostras complexas. A fibra foi sintetizada num capilar, em que os reagentes de síntese (estradiol como MM, MAA, AIBN, TRIM e acetonitrila) foram colocados para que ocorresse o processo de polimerização. Posteriormente, a fibra recoberta foi retirada do capilar, colocada em um tubo PEEK (tubo utilizado em sistemas cromatográficos) e instalada num HPLC com sistema multidimensional para que houvesse a pré-concentração dos analitos em um primeiro estágio e extração num segundo. O método apresentou bom resultado com relação à seletividade e grande potencial para análise em matrizes complexas com mínimo pré-tratamento ${ }^{[143]}$.

Figueiredo et al. propuseram o emprego de uma sonda de MIP para a extração de fenotiazínicos em amostras de plasma humano. Os autores sintetizaram um MIP seletivo à clorpromazina e promoveram a fixação do polímero em um filme de cola epóxido sobre uma espátula de vidro. Depois da secagem a sonda foi mergulhada na amostra para extração e colocada embaixo do spray sónico da técnica EASI (easy ambiente sonic spray ionization) para dessorção, ionização e análise por espectrometria de mas- sas. Bons resultados foram obtidos para análise semiquantitativa de 5 fenotiazinas com limites de quantificação da ordem de $1 \mu \mathrm{mol} \mathrm{L} \mathrm{L}^{-1[144]}$.

\section{Conclusões}

Como pôde ser visto, há hoje diversas possibilidades para o emprego de MIPs em preparo de amostras, o que certamente é resultado de avanços nas metodologias de síntese e nas configurações dos sistemas de extração. Essa constatação nos permite concluir ainda que os MIPs deixaram de ser uma tendência promissora em Ciência de Materiais para realmente se tornarem uma opção vantajosa na solução de problemas no preparo de amostras. Ademais, é certo que essa tecnologia ainda carece de evolução principalmente no sentido de melhoria da seletividade e outras caraterísticas relevantes em processos de extração. Algumas aplicações ainda são restritas, como, por exemplo, o reconhecimento molecular de proteínas, devido à dificuldade de se moldar sítios específicos para macromoléculas e a extração direta de analitos em fluidos proteicos devido à inevitável impregnação de proteínas no polímero. Finalmente, ousamos ainda destacar como tendência o emprego de MIP na análise direta de classes de compostos estruturalmente semelhantes por espectrometria de massas e sem separação cromatográfica, uma vez que a extração se restringe à classe, evitando assim problemas de supressão iônica.

\section{Agradecimentos}

Os autores agradecem à Fundação de Amparo à Pesquisa do Estado de Minas Gerais (FAPEMIG) projetos CDS-APQ-01323-09 e CDS-APQ-01612-10, ao Conselho Nacional de Desenvolvimento Científico e Tecnológico (CNPq), à Coordenação de Aperfeiçoamento 
de Pessoal de Nível Superior (CAPES) e à Financiadora de Estudos e Projetos (FINEP) o suporte financeiro.

\section{Referências}

1 Majores RE. An overview of sample preparation. LC-GC 1991; 9:16-20.

2 Smith RM. Before the injection - modern methods of sample preparation for separation techniques. Journal of Chromatography A 2003; 1000:3-27. http://dx.doi. org/10.1016/S0021-9673(03)00511-9

3 Kataoka H. New trends in sample preparation for clinical and pharmaceutical analysis. Trends in Analytical Chemistry 2003; 22:232-244. http://dx.doi. org/10.1016/S0165-9936(03)00402-3

4 Queiroz SCN, Collins CH, Jardim ICS. Métodos de extração e/ou concentração de compostos encontrados em fluidos biológicos para posterior determinação cromatográfica. Química Nova 2001; 24:68-76.

5 Papp R, Mullett WM, Kwong E. A method for the direct analysis of drug compounds in plasma using a single restricted access material (RAM) column. Journal of Pharmaceutical and Biomedical Analysis 2004; 36:457-464. PMid:15522518. http://dx.doi. org/10.1016/j.jpba.2004.07.029

6 Anderson JA. High performance liquid chromatography (direct injection techniques). Clinical Chemistry 1993; 65: 434-443.

7 Pawliszyn J. Unified theory of extraction. In: Pawliszyn J, editor. Sampling and sample preparation for field and laboratory. Elsevier; 2002. p. 353.

8 Ramos L, Smith RM. Preface. Journal of Chromatography A 2007; 1152:1. http://dx.doi. org/10.1016/j.chroma.2007.03.041

9 Ramos L, Smith RM. Preface. Journal of Chromatography A 2007; 1153:1. http://dx.doi. org/10.1016/j.chroma.2007.03.041

10 Pedersen-Bjergaard S, Rasmussen KE. New sample preparation technologies. Analytical and Bioanalytical Chemistry 2009; 393:779 http://dx.doi.org/10.1007/ s00216-008-2493-y

11 Beltran A, Borrull F, Cormack PAG, Marce RM. Molecularly-imprinted polymers: useful sorbents for selective extractions. Trends in Analytical Chemistry 2010; 29:1363-1375. http://dx.doi.org/10.1016/j. trac.2010.07.020
12 Polyakov MW. Adsorption properties and structure of silica gel. Russian Journal of Physical Chemistry 1931; 2: 799-804.

13 Dickey FH.The Preparation of Specific Adsorbents. Proceedings of the National Academy of Sciences of the United States of America 1949; 35:227-229. http:// dx.doi.org/10.1073/pnas.35.5.227

14 Dickey FH. Specific Adsorption. The Journal of Physical Chemistry 1955; 59:695-707. http://dx.doi. org/10.1021/j150530a006

15 Wulff G, Sarhan A. Über die Anwendung von enzymanalog gebauten Polymeren zur Racemattrennung. Angewandte Chemie 1972; 84:341. http://dx.doi.org/10.1002/ange.19720840838

16 Arshady R, Mosbach K. Synthesis of substrateselective polymers by host-guest polymerization. Macromolecular Chemistry and Physics 1981; 182:687692. http://dx.doi.org/10.1002/macp.1981.021820240

17 Norrlöw O, Glad M, Mosbach K. Acrylic polymer preparations containing recognition sites obtained by imprinting with substrates. Journal of Chromatography A 1984; 299:29-41. http://dx.doi.org/10.1016/S00219673(01)97819-7

18 Alexander C, Andersson HS, Andersson LI, Ansell RJ, Kirsch N, Nicholls IA et al. Molecular imprinting science and technology: a survey of the literature for the years up to and including 2003. Journal of Molecular Recognition 2006; 19:106-180. PMid:16395662. http:// dx.doi.org/10.1002/jmr.760

19 Andersson LI, Paprica A, Arvidsson T. A highly selective solid phase extraction sorbent for pre-concentration of sameridine made by molecular imprinting. Chromatographia 1997; 46:57-62. http:// dx.doi.org/10.1007/BF02490930

20 Walshe M, Howarth J, Kelly MT, O’Kennedy R, Smythet MR. The preparation of a molecular imprinted polymer to 7- hydroxycoumarin and its use as a solidphase extraction material Journal of Pharmaceutical and Biomedical Analysis 1997; 16:319-325. http:// dx.doi.org/10.1016/S0731-7085(97)00043-5

21 Masqué N, Marcé RM, Borrull F, Cormack PA, Sherrington DC. Synthesis and Evaluation of a Molecularly Imprinted Polymer for Selective On-Line Solid-Phase Extraction of 4-Nitrophenol from Environmental Water. Analytical Chemistry 2000; 72:4122-4126. http://dx.doi.org/10.1021/ac0000628

22 Mayes AG, Mosbach K. Molecularly imprinted polymers: useful materials for analytical chemistry? Trends in Analytical Chemistry 1997; 16:321-332. http://dx.doi.org/10.1016/S0165-9936(97)00037-X 
23 Ye L, Mosbach K. The Technique of Molecular Imprinting - Principle, State of the Art, and Future Aspects. Journal of Inclusion Phenomena and Macrocyclic Chemistry 2001; 41:107-113. http://dx.doi. org/10.1023/A:1014498404292

24 Andersson LI. Molecular imprinting for drug bioanalysis: A review on the application of imprinted polymers to solid-phase extraction and binding assay. Journal of Chromatography B: Biomedical Sciences and Applications 2000a; 739:163-173. http://dx.doi. org/10.1016/S0378-4347(99)00432-6

25 Sellergren B. Direct Drug Determination by Selective Sample Enrichment on an Imprinted Polymer. Analytical Chemistry 1994; 66:1578-1582. http:// dx.doi.org/10.1021/ac00081a036

26 Vitor RV, Martins MCG, Figueiredo EC, Martins I. Application of molecularly imprinted polymer solidphase extraction for salivary cotinine. Analytical and Bioanalytical Chemistry 2011; 400:2109-2117. PMid:21448605. http://dx.doi.org/10.1007/s00216011-4870-1

27 Javanbakhta M, Attaranb AM, Namjumanesha $\mathrm{MH}$, Esfandyari-Manesha M, Akbari-Aderganic B. Solidphase extraction of tramadol from plasma and urine samples using a novel water-compatible molecularly imprinted polymer. Journal of Chromatography $B$ 2010; 878:1700-1706. PMid:20452295. http://dx.doi. org/10.1016/j.jchromb.2010.04.006

28 Gholivand MB, Khodadadian M. Rationally designed molecularly imprinted polymers for selective extraction of methocarbamol from human plasma. Talanta 2011; 85:1680-1688. PMid:21807239. http:// dx.doi.org/10.1016/j.talanta.2011.06.066

29 Yang J, Hu Y, Cai JB, Zhu XL, Su QD, Hu YQ et al. Selective hair analysis of nicotine by molecular imprinted solid-phase extraction: An application for evaluating tobacco smoke exposure. Food and Chemical Toxicology 2007; 45:896-903. PMid:17222493. http:// dx.doi.org/10.1016/j.fct.2006.11.010

30 Xie J, Chen L, Li C, Xu X. Selective extraction of functional components derived from herb in plasma by using a molecularly imprinted polymer based on 2,2-bis(hydroxymethyl)butanol trimethacrylate. Journal of Chromatography B 2003; 788:233-242. http://dx.doi.org/10.1016/S1570-0232(02)00796-1

31 El-Sheikh AH, Al-Quse RW, El-Barghouthi MI, Al-Masri FS. Derivatization of 2-chlorophenol with 4-amino-anti-pyrine: A novel method for improving the selectivity of molecularly imprinted solid phase extraction of 2-chlorophenol from water.Talanta
2010; 83:667-673. PMid:21111190. http://dx.doi. org/10.1016/j.talanta.2010.10.022

32 Dai C, Zhou X, Zhang Y, Liu S, Zhang J. Synthesis by precipitation polymerization of molecularly imprinted polymer for the selective extraction of diclofenac from water samples. Journal of Hazardous Materials 2011; 198:175-181. PMid:22050930. http://dx.doi. org/10.1016/j.jhazmat.2011.10.027

33 Núñez L, Turiel E, Martin-Esteban A, Tadeo JL. Molecularly imprinted polymer for the extraction of parabens from environmental solid samples prior to their determination by high performance liquid chromatography-ultraviolet detection. Talanta 2010; 80:1782-1788. PMid:20152411. http://dx.doi. org/10.1016/j.talanta.2009.10.023

34 Dong X, Wang N, Wang S, Zhang X, Fan Z. Synthesis and application of molecularly imprinted polymer on selective solid-phase extraction for the determination of monosulfuron residue in soil. Journal of Chromatography A 2004; 1057:13-19. PMid:15584218. http://dx.doi.org/10.1016/j.chroma.2004.09.036

35 Ferrer I, Lanza F, Tolokán A, Horvath V, Sellergren B, Horvai G et al. Selective Trace Enrichment of Chlorotriazine Pesticides from Natural Waters and Sediment Samples Using Terbuthylazine Molecularly Imprinted Polymers. Analytical Chemistry 2000; 72:3934-3941. PMid:10959985. http://dx.doi. org/10.1021/ac000015f

36 Turiel E, Martín-Esteban A. Molecularly imprinted polymers for sample preparation: A review. Analytica Chimica Acta 2010; 668:87-99. PMid:20493285. http:// dx.doi.org/10.1016/j.aca.2010.04.019

37 Baggiani C, Baravalle P, Giovannoli C, Anfossi L, Giraudi G. Molecularly imprinted polymer/cryogel composites for solid-phase extraction of bisphenol A from river water and wine. Analytical and Bioanalytical Chemistry 2010; 397:815-822. PMid:20225052. http:// dx.doi.org/10.1007/s00216-010-3591-1

38 She Y, Cao W, Shi X, Lv X, Liu J, Wang R et al. Classspecific molecularly imprinted polymers for the selective extraction and determination of sulfonylurea herbicides in maize samples by high-performance liquid chromatography-tandem mass spectrometry. Journal of Chromatography B 2010; 878:20472053. PMid:20598653. http://dx.doi.org/10.1016/j. jchromb.2010.05.038

39 Shi X, Meng Y, Liu J, Sun A, Li D, Yao C et al. Groupselective molecularly imprinted polymer solid-phase extraction for the simultaneous determination of six sulfonamides in aquaculture products. 
Journal of Chromatography B 2011; 879:10711076. PMid:21459054. http://dx.doi.org/10.1016/j. jchromb.2011.03.019

40 Baggiani C, Baravalle P, Giraudi G, Tozzi C. Molecularly imprinted solid-phase extraction method for the high-performance liquid chromatographic analysis of fungicide pyrimethanil in wine. Journal of Chromatography A 2007; 1141:158-164. PMid:17178127. http://dx.doi.org/10.1016/j. chroma.2006.12.016

41 Turiel E, Tadeo JL, Cormack PAG, Martin-Esteban A. HPLC imprinted-stationary phase prepared by precipitation polymerisation for the determination of thiabendazole in fruit. Analyst 2005; 130:1601-1607. PMid:16284658. http://dx.doi.org/10.1039/b511031a

Mohamed R, Richoz-Payot J, Gremaud E, Mottier P, Yilmaz E, Tabet J-C et al. Advantages of Molecularly Imprinted Polymers LC-ESI-MS/MS for the Selective Extraction and Quantification of Chloramphenicol in Milk-Based Matrixes. Comparison with a Classical Sample Preparation. Analytical Chemistry 2007; 79:9557-9565. PMid:18001131. http://dx.doi. org/10.1021/ac7019859

43 Andersson HS, Nicholls IA. A historical perspective of the development of molecular imprinting. In: Sellergren B, editor. Molecularly Imprinted Polymers: Man-made mimics of antibodies their applications in analytical chemistry. Elsevier; 2003. p. 1.

44 Silva RGC, Augusto F. Sol-gel molecular imprinted ormosil for solid-phase extraction of methylxanthines. Journal of Chromatography A 2006; 1114:216223. PMid:16616927. http://dx.doi.org/10.1016/j. chroma.2006.03.073

45 Lin CI, Joseph AK, Chang CK, Wang YC, Lee YD. Synthesis of molecular imprinted organic-inorganic hybrid polymer binding caffeine. Analytica Chimica Acta 2003; 481:175-180. http://dx.doi.org/10.1016/ S0003-2670(03)00095-3

46 Li F, Li J, Zhang S. Molecularly imprinted polymer grafted on polysaccharide microsphere surface by the sol-gel process for protein recognition. Talanta 2004; 74:1247-1255. PMid:18371777. http://dx.doi. org/10.1016/j.talanta.2007.08.032

47 Queirósa RB, Silva SO, Noronha JP, Frazão O, Jorge P, Aguilar G et al. Microcystin-LR detection in water by the Fabry-Pérot interferometer using an optical fibre coated with a sol-gel imprinted sensing membrane. Biosensors and Bioelectronics 2011; 26:3932-3937. PMid:21489775. http://dx.doi.org/10.1016/j. bios.2011.03.015
48 Li T, Chena PY, Niena PC, Lina CY, Vittal R, Lingb TR et al. Preparation of a novel molecularly imprinted polymer by the sol-gel process for sensing creatinine. Analytica Chimica Acta 2012; 711:83-90. http://dx.doi. org/10.1016/j.aca.2011.10.031

49 Golsefidia MA, Es'Haghia Z, Sarafraz-Yazdic A. Design, synthesis and evaluation of a molecularly imprinted polymer for hollow fiber-solid phase microextraction of chlorogenic acid in medicinal plants. Journal of Chromatography A 2012; 1229:2429. PMid:22307151. http://dx.doi.org/10.1016/j. chroma.2012.01.019

50 Hu C-H, Chou T-C. Albumin molecularly imprinted polymer with high template affinity - Prepared by systematic optimization in mixed organic/aqueous media. Microchemical Journal 2009; 91:53-58. http:// dx.doi.org/10.1016/j.microc.2008.07.005

51 Navarroa V, Romeroa MG, Sánchez JFF, Cormack PAG, Carretero AS, Gutiérrez AF. Synthesis of caffeic acid molecularly imprinted polymer microspheres and high-performance liquid chromatography evaluation of their sorption properties. Journal of Chromatography A 2011; 1218:7289-7296. PMid:21889151. http:// dx.doi.org/10.1016/j.chroma.2011.08.043

52 Thibert V, Legeay P, ChapuisHugon F, Pichon V. Synthesis and characterization of molecularly imprinted polymers for the selective extraction of cocaine and its metabolite benzoylecgonine from hair extract before LC-MS analysis. Talanta 2012; 88:412419. PMid:22265519. http://dx.doi.org/10.1016/j. talanta.2011.11.009

53 He J, Lv R, Zhan $\mathrm{H}$, Wang $\mathrm{H}$, Cheng J, Lu K et al. Preparation and evaluation of molecularly imprinted solid-phase micro-extraction fibers for selective extraction of phthalates in an aqueous sample. Analytica Chimica Acta 2010; 674:5358. PMid:20638499. http://dx.doi.org/10.1016/j. aca.2010.06.018

$54 \mathrm{Xu} \mathrm{S}$, Liab J, Chen LJ. Molecularly imprinted coreshell nanoparticles for determination of trace atrazine by reversible addition-fragmentation chain transfer surface imprinting. Journal of Materials Chemistry 2011; 21:4346-4351. http://dx.doi.org/10.1039/ c0jm03593a

55 Pan G, Ma Y, Zhang T, Guo X, Li C, Zhang H. Controlled synthesis of water-compatible molecularly imprinted polymer microspheres with ultrathin hydrophilic polymer shells via surface-initiated reversible addition-fragmentation chain transfer 
polymerization. Soft Matter 2011; 7:8428-8439. http:// dx.doi.org/10.1039/c1sm05497j

56 Kempe H, Kempe M. Development and Evaluation of Spherical Molecularly Imprinted Polymer Beads. Analytical Chemistry 2006; 78:3659-3666. PMid:16737221. http://dx.doi.org/10.1021/ac060068i

57 Walsh R, Osmani Q, Hughes H, Duggan P, McLoughlin P. Synthesis of imprinted beads by aqueous suspension polymerisation for chiral recognition of antihistamines. Journal of Chromatography $B$ 2011; 879:3523-3530. PMid:21982909. http://dx.doi. org/10.1016/j.jchromb.2011.09.036

58 López MMC, Pérez MCC, García MSD, Vilariãno JML, Rodríguez MVG, Losada LFB. Preparation, evaluation and characterization of quercetinmolecularly imprinted polymer for preconcentration and clean-up of catechins. Analytica Chimica Acta 2012; 721:68-78. PMid:22405302. http://dx.doi. org/10.1016/j.aca.2012.01.049

59 Balamurugan K, Gokulakrishnan K, Prakasam T. Preparation and evaluation of molecularly imprinted polymer liquid chromatography column for the separation of Cathine enantiomers. Saudi Pharmaceutical Journal 2012; 20:53-61. http://dx.doi. org/10.1016/j.jsps.2011.06.004

60 Sambe H, Hoshina K, Haginaka J. Molecularly imprinted polymers for triazine herbicides prepared by multi-step swelling and polymerization method: Their application to the determination of methylthiotriazine herbicides in river water. Journal of Chromatography A 2007; 1152:130-137. PMid:16999969. http://dx.doi. org/10.1016/j.chroma.2006.09.003

61 Haginaka J. Molecularly imprinted polymers as affinity-based separation media for sample preparation. Journal of Separation Science 2009; 32:1548-1565. PMid:19472278. http://dx.doi. org/10.1002/jssc.200900085

62 Soleimani M, Ghaderi S, Afshar MG, Soleimani S. Synthesis of molecularly imprinted polymer as a sorbent for solid phase extraction of bovine albumin from whey, milk, urine and serum. Microchemical Journal 2012; 100:1-7. http://dx.doi.org/10.1016/j. microc.2011.06.026

63 Vieira AC, Zampieri RA, Siqueira MEPB, Martins M, Figueiredo EC. Molecularly imprinted solidphase extraction and high-performance liquid chromatography with ultraviolet detection for the determination of urinary trans,trans-muconic acid: a comparison with ionic exchange extraction. Analyst
2012; 137:2462-2469. PMid:22479697. http://dx.doi. org/10.1039/c2an16215f

64 Franqui LS, Vieira AC, Maia PP, Figueiredo EC. Extração de ácido trans-trans mucônico urinário com polímeros de impressão molecular e análise por cromatografia gasosa - espectrometria de massas. Química Nova. In press. PMid:11618007.

65 Khorrami AR, Rashidpur AJ. Design of a new cartridge for selective solid phase extraction using molecularly imprinted polymers: Selective extraction of theophylline from human serum samples. Biosensors and Bioelectronics 2009; 25:647-651. PMid:19157845. http://dx.doi.org/10.1016/j.bios.2008.11.033

66 Shi X, Liu J, Sun A, Li D, Chen J. Group-selective enrichment and determination of pyrethroid insecticides in aquaculture seawater via molecularly imprinted solid phase extraction coupled with gas chromatography-electron capture detection. Journal of Chromatography A 2012; 1227:60-66. PMid:22265776. http://dx.doi.org/10.1016/j.chroma.2012.01.012

67 Barros LA, Martins I, Rath S. A selective molecularly imprinted polymer-solid phase extraction for the determination of fenitrothion in tomatoes. Analytical and Bioanalytical Chemistry 2010; 397:1355-1361. PMid:20333363. http://dx.doi.org/10.1007/s00216010-3629-4

68 Puoci F, Curcio M, Cirillo G, Iemma F, Spizzirri UG, Picci N. Molecularly imprinted solid-phase extraction for cholesterol determination in cheese products. Food Chemistry 2008; 106:836-842. http://dx.doi. org/10.1016/j.foodchem.2007.06.043

69 Jiang X, Zhao C, Jiang N, Zhang H, Liu M. Selective solid-phase extraction using molecular imprinted polymer for the analysis of diethylstilbestrol. Food Chemistry 2008; 108:1061-1067. http://dx.doi. org/10.1016/j.foodchem.2007.11.039

70 Figueiredo EC, Oliveira DM, Siqueira MEPB, Arruda MAZ. On-line molecularly imprinted solid-phase extraction for the selective spectrophotometric determination of nicotine in the urine of smokers. Analytica Chimica Acta 2009; 635:102-107. PMid:19200485. http://dx.doi.org/10.1016/j. aca.2008.12.045

71 Xu Z, Chen S, Huang W, Fang G, Pingzhu H, Wang S. Study on an on-line molecularly imprinted solidphase extraction coupled to high-performance liquid chromatography for separation and determination of trace estrone in environment. Analytical and Bioanalytical Chemistry 2009; 393:1273-1279. 
PMid:19104786. http://dx.doi.org/10.1007/s00216008-2544-4

72 Feng Q, Zhao L, Yan W, Ji F, Wei Y, Lin J. Molecularly imprinted solid-phase extraction and flowinjection chemiluminescence for trace analysis of 2,4-dichlorophenol in water samples. Analytical and Bioanalytical Chemistry 2008; 391:1073-1079. PMid:18425501. http://dx.doi.org/10.1007/s00216008-2059-z

73 Figueiredo EC, Sparrapan R, Sanvido GB, Santos MG, Arruda MAZ, Eberlin MN. Quantitation of drugs via molecularly imprinted polymer solid phase extraction and electrospray ionization mass spectrometry: benzodiazepines in human plasma. Analyst 2011; 136:3753-3757. PMid:21776492. http://dx.doi. org/10.1039/clan $15198 \mathrm{c}$

74 Yan H, Qiao F, Row KH. Molecularly Imprinted Monolithic Column for Selective On-Line Extraction of Enrofloxacin and Ciprofloxacin from Urine. Chromatographia 2009; 70:1087-1093. http://dx.doi. org/10.1365/s10337-009-1244-3

75 Zhao C, Guan X, Liu X, Zhang H. Synthesis of molecularly imprinted polymer using attapulgite as matrix by ultrasonic irradiation for simultaneous on-line solid phase extraction and high performance liquid chromatography determination of four estrogens. Journal of Chromatography A 2012; 1229:7278. http://dx.doi.org/10.1016/j.chroma.2012.01.042

76 Oliveira HM, Segundo MA, Lima JLFC, Miró M, Cerdà V. Exploiting automatic on-line renewable molecularly imprinted solid-phase extraction in lab-on-valve format as front end to liquid chromatography: application to the determination of riboflavin in foodstuffs. Analytical and Bioanalytical Chemistry 2010; 397:77-86. PMid:20191267. http:// dx.doi.org/10.1007/s00216-010-3522-1

77 Zhang Z, Zhang H, Hu Y, Yao S. Synthesis and application of multi-walled carbon nanotubesmolecularly imprinted sol-gel composite material for on-line solid-phase extraction and high-performance liquid chromatography determination of trace Sudan IV. Analytica Chimica Acta 2010; 661:173180. PMid:20113732. http://dx.doi.org/10.1016/j. aca.2009.12.024

78 Xu Z, Fang G, Wang S. Molecularly imprinted solid phase extraction coupled to high-performance liquid chromatography for determination of trace dichlorvos residues in vegetables. Food Chemistry 2010; 119:845-850. http://dx.doi.org/10.1016/j. foodchem.2009.08.047
79 Cacho C, Turiel E, Pérez-Conde C. Molecularly imprinted polymers: An analytical tool for the determination of benzimidazole compounds in water samples. Talanta 2009; 78:1029-1035. PMid:19269468. http://dx.doi.org/10.1016/j.talanta.2009.01.007

80 Melo LP, Queiroz MEC. Simultaneous analysis of parabens in cosmetic products by stir bar sorptive extraction and liquid chromatography. Journal of Separation Science 2010; 33:1849-1855. PMid:20491059. http://dx.doi.org/10.1002/ jssc. 201000024

81 Zhu X, Zhu Q. Molecular imprinted Nylon-6 stir bar as a novel extraction technique for enantioseparation of amino acids. Journal of Applied Polymer Science 2008; 109:2665-2670. http://dx.doi.org/10.1002/app.27557

82 Gomez-Caballero A, Guerreiro A, Karim K, Piletsky S, Goicolea MA, Barrio RJ. Chiral imprinted polymers as enantiospecific coatings of stir bar sorptive extraction devices. Biosensors and Bioelectronics 2011; 28:25-32. PMid:21831628. http://dx.doi.org/10.1016/j. bios.2011.06.048

83 Yang L, Zhao X, Zhou J. Selective enrichment and determination of nicosulfuron in water and soil by a stir bar based on molecularly imprinted polymer coatings. Analytica Chimica Acta 2010; 670:7277. PMid:20685419. http://dx.doi.org/10.1016/j. aca.2010.04.041

84 Wang S, Wei J, Hao T, Guo Z. Determination of ractopamine in pork by using electrochemiluminescence inhibition method combined with molecularly imprinted stir bar sorptive extraction. Journal of Electroanalytical Chemistry 2012; 664:146-151. http://dx.doi.org/10.1016/j. jelechem.2011.11.011

$85 \mathrm{Xu} \mathrm{Z,} \mathrm{Hu} \mathrm{Y,} \mathrm{Hu} \mathrm{Y,} \mathrm{Li} \mathrm{G.} \mathrm{Investigation} \mathrm{of} \mathrm{ractopamine}$ molecularly imprinted stir bar sorptive extraction and its application for trace analysis of $\beta 2$-agonists in complex samples. Journal of Chromatography $A$ 2010; 1217:3612-3618. PMid:20399437. http://dx.doi. org/10.1016/j.chroma.2010.03.046

$86 \mathrm{Hu} \mathrm{Y,} \mathrm{Li} \mathrm{J,} \mathrm{Hu} \mathrm{Y,} \mathrm{Li} \mathrm{G.} \mathrm{Development} \mathrm{of} \mathrm{selective}$ and chemically stable coating for stir bar sorptive extraction by molecularly imprinted technique. Talanta 2010; 82:464-470. PMid:20602921. http:// dx.doi.org/10.1016/j.talanta.2010.04.057

87 Xu Z, Song C, Hu Y, Li G. Molecularly imprinted stir bar sorptive extraction coupled with high performance liquid chromatography for trace analysis of sulfa drugs in complex samples. Talanta 2011; 85:97- 
103. PMid:21645676. http://dx.doi.org/10.1016/j. talanta.2011.03.041

$88 \mathrm{Hu}$ Y, Li J, Li G. Synthesis and application of a novel molecularly imprinted polymer-coated stir bar for microextraction of triazole fungicides in soil. Journal of Separation Science 2011; 34:1190-1197. PMid:21491601. http://dx.doi.org/10.1002/ jssc. 201100068

89 Zhang Z, Yang MJ, Pawliszyn J. Solid-Phase Microextraction. A Solvent-Free Alternative for Sample Preparation. Analytical Chemistry 1994; 66:844A-853A. http://dx.doi.org/10.1021/ ac00089a001

90 Tamayo FG, Turiel E, Esteban AM. Molecularly imprinted polymers for solid-phase extraction and solid-phase microextraction: Recent developments and future trends. Journal of Chromatography A 2007; 1152:32-40. PMid:17010356. http://dx.doi. org/10.1016/j.chroma.2006.08.095

91 Djozan D, Ebrahimi B, Mahkam M, Farajzadeh MA. Evaluation of a new method for chemical coating of aluminum wire with molecularly imprinted polymer layer. Application for the fabrication of triazines selective solid-phase microextraction fiber. Analytica Chimica Acta 2010; 674:40-48. PMid:20638497. http:// dx.doi.org/10.1016/j.aca.2010.06.006

92 Qiu L, Liua W, Huangb M, Zhanga L. Preparation and application of solid-phase microextraction fiber based on molecularly imprinted polymer for determination of anabolic steroids in complicated samples. Journal of Chromatography A 2010; 1217:7461-7470. PMid:20965510. http://dx.doi.org/10.1016/j. chroma.2010.08.056

93 Prasad BB, Tiwari MP, Madhuri R, Sharma PS. Development of a highly sensitive and selective hyphenated technique (molecularly imprinted microsolid phase extraction fiber-molecularly imprinted polymer fiber sensor) for ultratrace analysis of folic acid. Analytica Chimica Acta 2010; 662:14-22. PMid:20152260. http://dx.doi.org/10.1016/j. aca.2009.12.037

$94 \mathrm{Hu}$ X, Pana J, Hua Y, Li G. Preparation and evaluation of propranolol molecularly imprinted solid-phase microextraction fiber for trace analysis of $\beta$-blockers in urine and plasma samples. Journal of Chromatography A 2009; 1216:190-197. PMid:19084232. http://dx.doi. org/10.1016/j.chroma.2008.11.064

95 Djozan D, Ebrahimi B. Preparation of new solid phase micro extraction fiber on the basis of atrazinemolecular imprinted polymer: Application for GC and GC/MS screening of triazine herbicides in water, rice and onion. Analytica Chimica Acta 2008; 616:152159. PMid:18482598. http://dx.doi.org/10.1016/j. aca.2008.04.037

96 Hu Y, Wang Y, Chen X, Hu Y, Li G. A novel molecularly imprinted solid-phase microextraction fiber coupled with high performance liquid chromatography for analysis of trace estrogens in fishery samples. Talanta 2010; 80:2099-2105. PMid:20152458. http://dx.doi. org/10.1016/j.talanta.2009.11.015

97 Hu X, Daia G, Huanga J, Yea T, Fanb H, Youwena $\mathrm{T}$ et al. Molecularly imprinted polymer coated on stainless steel fiber for solid-phase microextraction of chloroacetanilide herbicides in soybean and corn. Journal of Chromatography A 2010; 1217:5875-5882. PMid:20708736. http://dx.doi.org/10.1016/j. chroma.2010.07.011

98 Barahona F, Turiel E, Esteban AM. Supported liquid membrane-protected molecularly imprinted fibre for solid-phase microextraction of thiabendazole. Analytica Chimica Acta 2011; 694:83-89. PMid:21565306. http://dx.doi.org/10.1016/j. aca.2011.03.052

$99 \mathrm{Hu} \mathrm{Y}$, Wang Y, Hu Y, Li G. Liquid-liquid-solid microextraction based on membrane-protected molecularly imprinted polymer fiber for trace analysis of triazines in complex aqueous samples. Journal of Chromatography A 2009; 1216:8304-8311. PMid:19819459. http://dx.doi.org/10.1016/j. chroma.2009.09.063

100 Feng Q, Zhaoa L, Linb J. Molecularly imprinted polymer as micro-solid phase extraction combined with high performance liquid chromatography to determine phenolic compounds in environmental water samples. Analytica Chimica Acta 2009; 650:7076. PMid:19720176. http://dx.doi.org/10.1016/j. aca.2009.04.016

101 Tarley CRT, Sotomayor LT, Kubota LT. Polímeros biomiméticos em química analítica. Parte 2: aplicações de MIP ("Molecularly Imprinted Polymers") no desenvolvimento de sensores químicos. Química Nova 2005; 28:1087-1101. http://dx.doi.org/10.1590/S010040422005000600025

102 Wang X, Maoa H, Huang W, Guan W, Zoub X, Pan J et al. Preparation of magnetic imprinted polymer particles via microwave heating initiated polymerization for selective enrichment of 2-amino-4-nitrophenol from aqueous solution. Chemical Engineering Journal 2011; 178:85-92. http://dx.doi.org/10.1016/j.cej.2011.10.015 
103 Wang X, Pan J, Guan W, Zou X, Huo P, Yan Y et al. Selective recognition of sesamol using molecularly imprinted polymers containing magnetic wollastonite. Journal of Separation Science 2011; 34:32873294. PMid:21997999. http://dx.doi.org/10.1002/ jssc. 201100358

104 Pan J, Xu L, Dai J, Li X, Hang H, Huo P et al. Magnetic molecularly imprinted polymers based on attapulgite/ Fe3O4 particles for the selective recognition of 2,4-dichlorophenol. Chemical Engineering Journal 2011; 174:68-75. http://dx.doi.org/10.1016/j. cej.2011.08.046

105 Pan J, Yao H, Xu L, Ou H, Huo P, Li X, Yan Y. Selective Recognition of 2,4,6-Trichlorophenol by Molecularly Imprinted Polymers Based on Magnetic Halloysite Nanotubes Composites. The Journal of Physical Chemistry C 2011; 115:5440-5449. http://dx.doi. org/10.1021/jp111120x

106 Wang S, Li Y, Ding M, Wu X, Xu J, Wang R et al. Self-assembly molecularly imprinted polymers of $17 \beta$-estradiol on the surface of magnetic nanoparticles for selective separation and detection of estrogenic hormones in feeds. Journal of Chromatography $B$ 2011; 879:2595-2600. PMid:21820977. http://dx.doi. org/10.1016/j.jchromb.2011.07.017

107 Ding M, Wu X, Yuan L, Wang S, Li Y, Wang R et al. Synthesis of core-shell magnetic molecularly imprinted polymers and detection of sildenafil and vardenafil in herbal dietary supplements. Journal of Hazardous Materials 2011; 191:177-183. PMid:21555181. http:// dx.doi.org/10.1016/j.jhazmat.2011.04.058

108 Hu Y, Li Y, Liu R, Tan W, Li G. Magnetic molecularly imprinted polymer beads prepared by microwave heating for selective enrichment of $\beta$-agonists in pork and pig liver samples. Talanta 2011; 84:462-470. PMid:21376974. http://dx.doi.org/10.1016/j. talanta.2011.01.045

109 Zhang X, Chena L, Xua Y, Wanga H, Zenga Q, Zhaoa $Q$ et al. Determination of $\beta$-lactam antibiotics in milk based on magnetic molecularly imprinted polymer extraction coupled with liquid chromatographytandem mass spectrometry. Journal of Chromatography B 2010; 878:3421-3426. PMid:21095165. http://dx.doi. org/10.1016/j.jchromb.2010.10.030

110 Gai QQ, Qua F, Zhanga T, Zhang Y. J. The preparation of bovine serum albumin surface-imprinted superparamagnetic polymer with the assistance of basic functional monomer and its application for protein separation. Journal of Chromatography A
2011; 1218:3489-3495. PMid:21511265. http://dx.doi. org/10.1016/j.chroma.2011.03.069

111 Jing T, Xiaa H, Guanb Q, Lu W, Dai Q, Niu J et al. Rapid and selective determination of urinary lysozyme based on magnetic molecularly imprinted polymers extraction followed by chemiluminescence detection. Analytica Chimica Acta 2011; 692:73-79. PMid:21501714. http://dx.doi.org/10.1016/j. aca.2011.02.057

112 Zhang Z, Tan W, Hu Y, Li G. Simultaneous determination of trace sterols in complicated biological samples by gas chromatography-mass spectrometry coupled with extraction using $\beta$-sitosterol magnetic molecularly imprinted polymer beads. Journal of Chromatography A 2011; 1218:42754283. PMid:21632061. http://dx.doi.org/10.1016/j. chroma.2011.05.022

113 Jing T, Du H, Dai Q, Xia H, Niu J, Hao Q et al. Magnetic molecularly imprinted nanoparticles for recognition of lysozyme. Biosensors and Bioelectronics 2010; 26:301-306. PMid:20829022. http://dx.doi. org/10.1016/j.bios.2010.08.044

114 Wang X, Wanga L, Hea X, Zhanga Y, Chena L. A molecularlyimprinted polymer-coated nanocomposite of magnetic nanoparticles for estrone recognition. Talanta 2009; 78:327-332. PMid:19203590. http:// dx.doi.org/10.1016/j.talanta.2008.11.024

115 Chen L, Zhanga X, Xua Y, Dub X, Sunb X, Suna L et al. Determination of fluoroquinolone antibiotics in environmental water samples based on magnetic molecularly imprinted polymer extraction followed by liquid chromatography-tandem mass spectrometry. Analytica Chimica Acta 2010; 662:3138. PMid:20152262. http://dx.doi.org/10.1016/j. aca.2010.01.001

116 Chen L, Zhang X, Sun L, Xu Y, Zeng Q, Wang H et al. Fast and Selective Extraction of Sulfonamides from Honey Based on Magnetic Molecularly Imprinted Polymer. Journal of Agricultural and Food Chemistry 2009; 57:10073-10080. PMid:19817457. http://dx.doi. org/10.1021/jf902257d

117 Chen L, Liu J, Zeng Q, Wang H, Yu A, Zhang H et al. Preparation of magnetic molecularly imprinted polymer for the separation of tetracycline antibiotics from egg and tissue samples. Journal of Chromatography A 2009; 1216:3710-3719. PMid:19268956. http:// dx.doi.org/10.1016/j.chroma.2009.02.044

118 Prieto A, Schrader S, Bauer C, Möder M. Synthesis of a molecularly imprinted polymer and its application for microextraction by packed sorbent for the 
determination of fluoroquinolone related compounds in water. Analytica Chimica Acta 2011; 685:146152. PMid:21168563. http://dx.doi.org/10.1016/j. aca.2010.11.038

119 Prieto A, Vallejo A, Zuloaga O, Paschke A, Sellergen $\mathrm{B}$, Schillinger $\mathrm{E}$ et al. Selective determination of estrogenic compounds in water by microextraction by packed sorbents and a molecularly imprinted polymer coupled with large volume injection-inport-derivatization gas chromatography-mass spectrometry. Analytica Chimica Acta 2011; 703:PMid:21843673. http://dx.doi.org/10.1016/j. aca.2011.07.00741-51.

120 Qiao F, Sun H. J. Simultaneous extraction of enrofloxacin and ciprofloxacin from chicken tissue by molecularly imprinted matrix solid-phase dispersion. Journal of Pharmaceutical and Biomedical Analysis 2010; 53:795-798. PMid:20619993. http://dx.doi. org/10.1016/j.jpba.2010.06.008

$121 \mathrm{Hu} \mathrm{Y,} \mathrm{Liu} \mathrm{R,} \mathrm{Li} \mathrm{R,} \mathrm{Li} \mathrm{G.} \mathrm{Investigation} \mathrm{of} \mathrm{ractopamine-}$ imprinted polymer for dispersive solid-phase extraction of trace $\beta$-agonists in pig tissues. Journal of Separation Science 2010; 33:20172025. PMid:20533342. http://dx.doi.org/10.1002/ jssc. 201000063

122 Guo L, Guan M, Zhao C, Zhang H. Molecularly imprinted matrix solid-phase dispersion for extraction of chloramphenicol in fish tissues coupled with high-performance liquid chromatography determination. Analytical and Bioanalytical Chemistry 2008; 392:1431-1438. PMid:18949463. http://dx.doi. org/10.1007/s00216-008-2454-5

123 Sun H, Qiao F, Liu G, Liang S. Simultaneous isolation of six fluoroquinolones in serum samples by selective molecularly imprinted matrix solid-phase dispersion. Analytica Chimica Acta 2008; 625:154159. PMid:18724989. http://dx.doi.org/10.1016/j. aca.2008.07.025

124 Yan H, Qiao F, Row KH. Molecularly Imprinted-Matrix Solid-Phase Dispersion for Selective Extraction of Five Fluoroquinolones in Eggs and Tissue. Analytical Chemistry 2007; 79:8242-8248. PMid:17918913. http://dx.doi.org/10.1021/ac070644q

125 Qiao F, Yan H. Simultaneous analysis of fluoroquinolones and xanthine derivatives in serum by molecularly imprinted matrix solid-phase dispersion coupled with liquid chromatography. Journal of Chromatography B 2011; 879:35513555. PMid:21978534. http://dx.doi.org/10.1016/j. jchromb.2011.09.040
126 Yan H, Wang H, Qiao J, Yang G. Molecularly imprinted matrix solid-phase dispersion combined with dispersive liquid-liquid microextraction for the determination of four Sudan dyes in egg yolk. Journal of Chromatography A 2011; 1218:21822188. PMid:21388626. http://dx.doi.org/10.1016/j. chroma.2011.02.042

127 Wang T, Tong J, Sun M, Chen L. Fast and selective extraction of chloramphenicol from soil by matrix solid-phase dispersion using molecularly imprinted polymer as dispersant. Journal of Separation Science 2011; 34:1886-1892. PMid:21674791. http://dx.doi. org/10.1002/jssc.201100046

128 Boos KS, Fleischer CT. Multidimensional on-line solid-phase extraction (SPE) using restricted access materials (RAM) in combination with molecular imprinted polymers (MIP). Analytical Chemistry 2001; 371:16-20. PMid:11605750. http://dx.doi. org/10.1007/s002160100831

129 Koeber R, Fleischer C, Lanza F, Boos KS, Sellergren B, Barcelo D. Evaluation of a Multidimensional Solid-Phase Extraction Platform for Highly Selective On-Line Cleanup and High-Throughput LC-MS Analysis of Triazines in River Water Samples Using Molecularly Imprinted Polymers. Analytical Chemistry 2001; 73:2437-2444. PMid:11403283. http://dx.doi. org/10.1021/ac001483s

130 Haginaka J, Takehira H, Hosoya K, Tanaka N. Uniform-sized molecularly imprinted polymer for (S)-naproxen selectively modified with hydrophilic external layer. Journal of Chromatography A 1999; 849:331-339. http://dx.doi.org/10.1016/S00219673(99)00570-1

131 Haginaka J, Sanbe H. Uniform-Sized Molecularly Imprinted Polymers for 2-Arylpropionic Acid Derivatives Selectively Modified with Hydrophilic External Layer and Their Applications to Direct Serum Injection Analysis. Analytical Chemistry 2000; 72:5206-5210. PMid:11080865. http://dx.doi. org/10.1021/ac0005215

132 Hoshina K, Horiyama S, Matsunaga H, Haginaka J. Simultaneous determination of non-steroidal antiinflammatory drugs in river water samples by liquid chromatography-tandem mass spectrometry using molecularly imprinted polymers as a pretreatment column. Journal of Pharmaceutical and Biomedical Analysis 2011; 55:916-922. PMid:21470812. http:// dx.doi.org/10.1016/j.jpba.2011.03.014

133 Hoshina K, Horiyama S, Matsunaga H, Haginaka J. Molecularly imprinted polymers for simultaneous 
determination of antiepileptics in river water samples by liquid chromatography-tandem mass spectrometry. Journal of Chromatography A 2009; 1216:49574962. PMid:19439306. http://dx.doi.org/10.1016/j. chroma.2009.04.071

134 Sambe H, Hoshina K, Hosoya K, Haginaka J. Simultaneous determination of bisphenol $\mathrm{A}$ and its halogenated derivatives in river water by combination of isotope imprinting and liquid chromatographymass spectrometry. Journal of Chromatography A 2006; 1134:16-23. PMid:16978634. http://dx.doi. org/10.1016/j.chroma.2006.08.072

135 Parisi OI, Cirillo G, Curcio M, Puoci F, Iemma F, Spizzirri UG et al. Surface modifications of molecularly imprinted polymers for improved template recognition in water media. Journal of Polymer Research 2010; 17:355-362. http://dx.doi. org/10.1007/s10965-009-9322-7

136 Puoci F, Iemma F, Cirillo G, Curcio M, Parisi OI, Spizzirri UG et al. New restricted access materials combined to molecularly imprinted polymers for selective recognition/release in water media. European Polymer Journal 2009; 45:1634-1640. http://dx.doi. org/10.1016/j.eurpolymj.2009.01.021

$137 \mathrm{Xu} \mathrm{W}$, Su S, Jiang P, Wang H, Dong X, Zhang M. Determination of sulfonamides in bovine milk with column-switching high performance liquid chromatography using surface imprinted silica with hydrophilic external layer as restricted access and selective extraction material. Journal of Chromatography A 2010; 1217:7198-7207. PMid:20934183. http://dx.doi.org/10.1016/j. chroma.2010.09.035

138 Hua K, Zhang L, Zhang Z, Guo Y, Guo T. Surface hydrophilic modification with a sugar moiety for a uniform-sized polymer molecularly imprinted for phenobarbital in serum. Acta Biomaterialia
2011; 7:3086-3093. PMid:21605708. http://dx.doi. org/10.1016/j.actbio.2011.05.006

139 Sergeyeva TA, Matuschewski H, Piletsky SA, Bendig J, Schedler U, Ulbricht M. Molecularly imprinted polymer membranes for substance-selective solidphase extraction from water by surface photo-grafting polymerization. Journal of Chromatography A 2001; 907:89-99. http://dx.doi.org/10.1016/S00219673(00)01053-0

140 Pap B-T, Horváth V, Tolokán A, Horvai G, Sellergren B. Effect of solvents on the selectivity of terbutylazine imprinted polymer sorbents used in solid-phase extraction. Journal of Chromatography A 2002; 973:112. http://dx.doi.org/10.1016/S0021-9673(02)01084-1

141 Suedee C-R, Srichana T, Chuchome T, Kongmark $\mathrm{U}$. Use of molecularly imprinted polymers from a mixture of tetracycline and its degradation products to produce affinity membranes for the removal of tetracycline from water. Journal of Chromatography $B$ 2004; 811:191-200. PMid:15522720.

142 Tan D-F, Deng M, Liu X, Zhao H, Li X, Quan X et al. Evaluation of a novel microextraction technique for aqueous samples: Porous membrane envelope filled with multiwalled carbon nanotubes coated with molecularly imprinted polymer. Journal of Separation Science 2011; 34:707-715. PMid:21312332. http:// dx.doi.org/10.1002/jssc.201000791

143 Zhong E-Q, Hu Y, Hu Y, Li G. Dynamic liquidliquid-solid microextraction based on molecularly imprinted polymer filaments on-line coupling to high performance liquid chromatography for direct analysis of estrogens in complex samples. Journal of Chromatography A 2012; 1241:13-20. PMid:22554413. http://dx.doi.org/10.1016/j.chroma.2012.04.017

144 Figueiredo EC, Sanvido GB, Arruda MAZ, Eberlin MN. Molecularly imprinted polymers as analyte sequesters and selective surfaces for easy ambient sonic-spray ionization. Analyst 2010; 135:726-730. PMid:20309446. http://dx.doi.org/10.1039/b923289c 


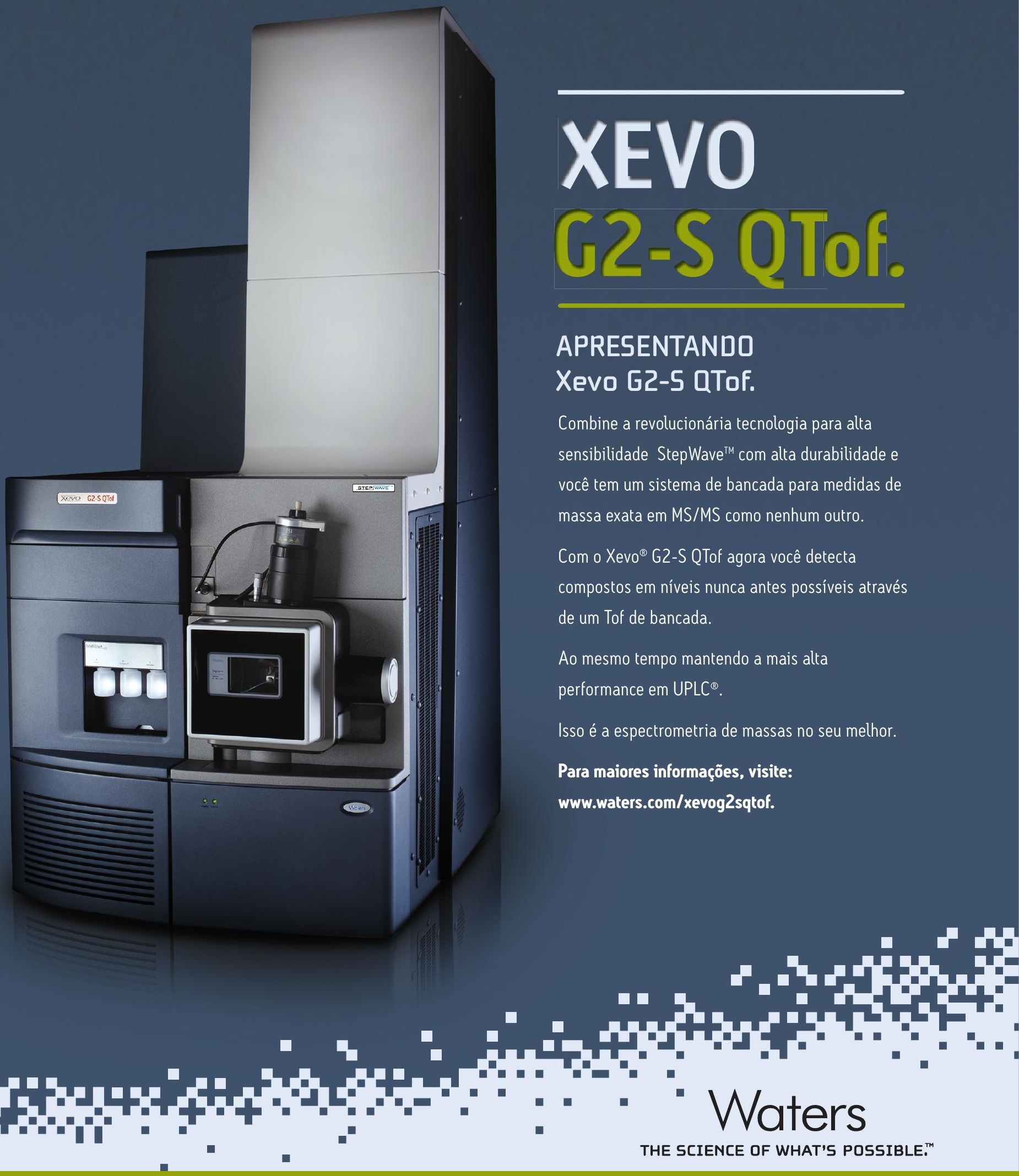

Pharmaceutical \& Life Sciences | Food | Environmental | Clinical | Chemical Materials 